\title{
Effect of Large Gas-Oil Capillary Pressure on Production: A Compositionally- Extended Black Oil Formulation
}

\author{
B. Nojabaei, University of Wyoming; N. Siripatrachai, R.T. Johns, T. Ertekin, The Pennsylvania State University
}

\begin{abstract}
Pore sizes are typically on the order of nanometers for many shale and tight rock oil reservoirs. Such small pores can affect the phase behavior of in situ oil and gas owing to large capillary pressure. Current black-oil simulation practice is to alter the unconfined black-oil data for a fixed mean pore size to generate confined black-oil data with a suppressed bubble-point pressure. This approach ignores compositional effects on interfacial tension and the impact of pore-size distribution (PSD) with variable phase saturations on capillary pressure and phase behavior.

In this paper, we develop a compositionally-extended black-oil model where we solve the compositional equations (gas, oil, and water components) directly so that black-oil data are a function of gas content in the oleic phase and gas-oil capillary pressure. The principle unknowns in the variable bubble-point fully-implicit formulation are oil pressure, overall gas composition, and water saturation. Flash calculations in the model are non-iterative and are based on $K$-values calculated explicitly from the black-oil data. The advantage of solving the black-oil model using the compositional equations is to increase robustness of the simulations owing to a variable bubble-point pressure that is a function of two parameters; gas content and capillary pressure. Leverett J-functions measured for the Bakken reservoir are used to establish the effective pore size- $P_{c}$-saturation relationship, where the effective pore size depends on gas saturation, which is the non-wetting phase saturation. The input fluid data to the simulator, e.g. interfacial tension (IFT), phase densities and viscosities, are precalculated as functions of pressure from the Peng-Robinson equation of state (PREOS) for three fixed pore sizes. During the simulation, at any pressure and saturation, fluid properties are calculated at the effective pore radius by using linear interpolation between these three data sets. We compare the results of the compositionally-extended black oil model with those of a fully-implicit eight-component compositional model that we have also developed. The results for the Bakken reservoir show that including PSD in the model can increase estimated recoveries by nearly $10 \%$ for initially undersaturated reservoirs while the increase can be over $100 \%$ for initially saturated reservoirs. Capillary pressure significantly increases the original oil-in-place (OOIP) for reservoirs that would otherwise be initially saturated leading to larger oil production.
\end{abstract}

\section{Introduction}

Ultra-low permeability formations and shale reservoirs are significant contributors to the total oil and gas production in the United States. According to Kuila and Prasad (2011), the matrix in shale reservoirs consists of pores ranging in size from micro-pores with less than 2 nanometers $(\mathrm{nm})$ in diameter to meso-pores with diameters in the range of 2-50 $\mathrm{nm}$. Such small pores are associated with high capillary pressure, which can influence the phase behavior of reservoir fluids (Nojabaei et al. 2013).

The effect of capillary pressure on the phase behavior of reservoir fluids has been investigated from a theoretical perspective by Brusllovsky (1992) and Ping et al. (1996). Because of the growing importance of unconventional reservoirs, researchers have recently focused on how capillary pressure can affect the phase behavior of crudes in ultra-low permeability reservoirs and how this affects recovery. Nojabaei et al. (2013) investigated the effect of nanometer pores on the shape of the phase envelope and saturation pressures. They concluded there can be a significant decrease in bubble-point pressure, but the dew-point pressure is increased or decreased depending on the portion of the saturation envelope examined. Oil recovery for the Bakken reservoir significantly increased when capillary pressure was included in their simulations. Production was simulated, however, using a fixed depressed bubble-point as input. The increase in recovery was mainly attributed to longer gas-free production in their paper. Firincioglu et al. (2012) calculated formation volume factors affected by capillary pressure and also recognized that bubble-point pressure is decreased. The main results of their paper were the calculation of formation volume factors in the presence of capillary pressure. Luchao et al. (2013) showed for pure fluids that if pore sizes are smaller than $10 \mathrm{~nm}$, critical properties of the hydrocarbon components could be modified to match the phase behavior using an equation-of-state. Such modifications can significantly change not only the bubble-point and dew-point curves, but also the critical point (the two-phase zone shrinks on a PT plot). Their approach is based on Monte Carlo molecular simulations and correlations previously developed by Singh et al. (2009) for pure fluids. Results using this approach may not be valid, however, for mixtures. Recently, Wang et al. (2014) conducted phase behavior experiments in micro- and nanosized channels and concluded that bubble-point pressure for pure components is significantly lower in nano-sized channels as compared to the micro-sized channels. They also examined a three-component system and concluded that in addition to capillary pressure effects, liberation of lighter components from the oleic phase to the vapor phase further suppresses the bubble-point pressure in the nano-sized channels. In a theoretical study, Ma and Jamili (2014) showed that fluid densities in nano-pores are higher than bulk densities. They modified the Peng-Robinson equation of state to fit the pure fluid data by 
applying the local density model to consider adsorption and solid-fluid interactions. They validated their model with the molecular simulation results of Singh et al. (2009) for pure fluids, but applied their method to both pure fluids and multicomponent mixtures.

Other papers have also attempted to account for the effect of tiny pores on oil production using reservoir simulation. Du et al. (2012) calculated black oil fluid properties, e.g. oil formation volume factor, viscosities and gas-oil ratio, which are affected by large capillary pressure. Similar to Nojabaei et al. (2013), they input the adjusted black oil data directly to a standard black-oil simulator and concluded that high capillary pressure increases production. The black-oil data were adjusted using only one value of capillary pressure based on a single pore radius making the simulations only approximate. That is, pore-size distribution and variable saturation-dependent capillary pressure were not considered. In a compositional reservoir simulation study by Wang et al. (2013), the effect of capillary pressure on production is investigated. Capillary pressure was calculated two ways, one with a fixed pore radius and the other using a Leverett J-function curve. Interfacial tension, however, appears to be fixed in their simulations. They also observed an increase in oil production caused by capillary pressure. Alharthy et al. (2013) made dual-porosity simulations where they applied the method based on the purecomponent correlations for shifting the critical properties developed by Singh et al. (2009). Firincioglu et al. (2013) developed a correlation to calculate bubble-point pressure suppression as a function of capillary pressure and solution gas-oil ratio. Using this correlation in a commercial black oil simulator, they concluded that confined fluid behavior has a positive impact on oil production for black oil reservoirs. Recently, Rezaveisi et al., (2015) included capillary pressure in flash calculations in an IMPEC simulator. They performed simulations for volatile oil and gas condensate reservoirs and examined the effect of high capillary pressure on production. They further showed that there is a maximum value of capillary pressure to achieve phase stability so that the pressure difference between gas and oil phases cannot be larger than this value. This limiting capillary pressure depends on pressure, temperature, and fluid composition. In most cases, however, the limiting capillary pressures are associated with very small pores $(1-2 \mathrm{~nm})$ where the use of a cubic equation-of-state is likely not warranted. Jin and Firoozabadi, (2016) showed that in pores greater than $10 \mathrm{~nm}$, the interface curvature affects the phase behavior of reservoir fluid and fluid phases are homogenous so conventional equation of states can be used. In this study, we limit pore sizes to a minimum of $10 \mathrm{~nm}$, and as a result, we are generally not concerned with instability associated with a limiting capillary pressure.

All previous research using the black-oil approach assumes capillary pressure as a function of a single pore size or has neglected composition-dependent gas-oil interfacial tension. In reality, porous media consists of a range of pore sizes so capillary pressure is a strong function of saturation.

In this paper, we propose a novel model to estimate production of shale reservoirs by fully incorporating the effect of saturation-dependent capillary pressure and pressure-dependent interfacial tensions in a black (or volatile)-oil model. The first section of this paper reviews the compositionally-extended black oil approach developed by Huan (1985), but without capillary pressure effects on phase behavior. This approach has significant advantages over the conventional black-oil solution because its numerical solution is continuous when the free gas phase appears or disappears as was discussed by Wong et al. (1987). Furthermore, as shown in this paper, the approach easily allows for a variable bubble-point formulation where the bubble-point (and all black-oil properties) is a function of both the amount of the gas component in the oleic phase and also the level of capillary pressure. To our knowledge, this is the first paper that uses a variable bubble-point formulation as a function of two parameters. Next, we show how to pre-calculate black oil fluid properties for Bakken oil using the PengRobinson equation of state (1976). The calculations are done in the presence of capillary pressure for three different pore sizes. The resulting black-oil data including interfacial tensions are tabulated for use in the simulations. The last section gives the results of simulations using the Bakken eight-component fluid. We compare the compositionally-extended black oil simulations to a fully compositional simulation that also includes the effect of capillary pressure on phase behavior. The comparison shows good agreement. The results from the pore-size distribution (PSD) approach are compared to those using a fixed pore size. A sensitivity analysis of oil production is done based on reservoir initial pressure. Finally we provide a more realistic example of production in oil shale reservoirs by including a discrete fracture in the reservoir.

\section{Methodology}

In this section, we illustrate the methodology used to simulate the production from an oil shale reservoir. First, the black oil fluid properties are pre-calculated using cubic equation-of-state (EOS) flash calculations of the Bakken crude oil at various levels of capillary pressure. These data are calculated as a function of pressure. Next, three-phase capillary pressures (oleic, vapor or gas, and aqueous or water) are estimated for an example reservoir based on mercury injection results with Bakken rock. Last, we demonstrate the use of this data in our new simulator and describe the compositionally-extended approach. As an overview, a flowchart demonstrating the simulation steps is presented in Figure 1. 


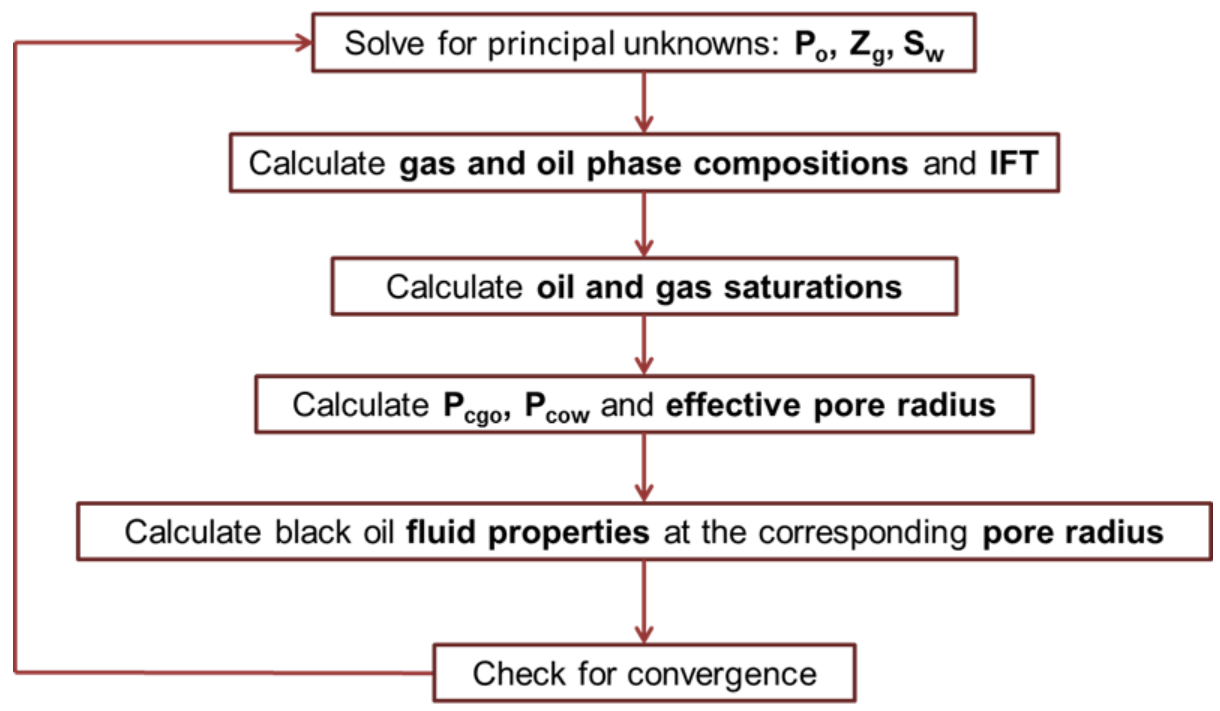

Figure 1- Flow chart for the compositionally-extended black oil simulator during each time step

\subsection{Input Black Oil Fluid Properties Affected by Nanometer Sized Pores}

Flash calculations that account for the effect of pore size and the resulting high capillary pressure (Nojabaei et al., 2013) are first made to calculate fluid properties such as gas and oil densities, viscosities, solution gas-oil ratio, volatile oil-gas ratio, and interfacial tension as a function of oil pressure. Because Bakken crude is classified as black oil, the volatile oil-gas ratio is relatively small, but inclusion of this parameter demonstrates the generality of the method, i.e. the method can be applied to volatile fluids as well. In the current methodology, these data are generated for three pore sizes where bubblepoint pressure is also calculated for each case. Oil pressure is assumed to be the reference phase pressure, while gas pressure is calculated using the Laplace equation given below,

$P_{g}=P_{o}+\frac{2 \sigma}{r}$.

Phase equilibrium is achieved when the component fugacities of the gas and oil phases are equal. That is,

$f_{i}^{o}\left(T, P_{o}, x_{1}, x_{2}, \ldots, x_{N_{C}}\right)=f_{i}^{g}\left(T, P_{g}, y_{1}, y_{2}, \ldots, y_{N_{C}}\right)$.

During pressure depletion, gas-oil interfacial tension varies significantly so that neglecting this change could lead to errors. Based on the flash calculations, we pre-calculate interfacial tensions as a function of pressure and use this data as input to the simulator.

Capillary pressure is not only a function of IFT but also saturation. We demonstrate the use of mercury injection tests of Bakken samples to derive the relationship between saturation, capillary pressure, and the effective pore radius at any saturation. In this way, fluid properties are considered as functions of pore radius and consequently functions of capillary pressure and saturation.

We use the flash calculation approach to determine the black- and volatile-oil properties, where the EOS model has been tuned to standard PVT data. First, the pressure is reduced in a constant composition expansion test to calculate oil and gas densities and viscosities. For pressures greater than the original bubble-point pressure, reservoir fluid is a single phase liquid and the oil composition does not change. Above the bubble-point pressure, oil densities and viscosities are nearly linear with pressure and the solution gas-oil ratio is constant. To calculate solution gas-oil and volatile oil-gas ratios at each pressure below the original bubble-point pressure, we flash the overall composition at that pressure to obtain equilibrium liquid and gas compositions. The liquid composition is flashed at standard conditions to determine the solution gas-oil ratio, while the equilibrium gas composition is then flashed to obtain the volatile oil-gas ratio. Solution gas-oil ratio is then the volume of gas at standard condition that evolves from the oil divided by the volume of oil at standard condition (SCF/STB). The volatile oil-gas ratio is the volume of oil at standard conditions that condenses from the gas divided by the volume of gas at standard conditions (STB/MMSCF). These fluid properties are functions of oil pressure in the standard black- or volatile-oil model.

Compositionally-extended black oil fluid properties (densities, viscosities, solution gas-oil ratios, and volatile oil-gas ratios) are calculated using the Peng-Robinson equation of state for pore sizes varying from $10 \mathrm{~nm}, 30 \mathrm{~nm}$, to infinitely large. 
These fluid properties, shown in Figures 2 to 7, are presented as functions of oil pressure. An infinite pore size corresponds to zero capillary pressure so that its influence on phase behavior becomes zero. Oil viscosity, oil density and volatile oil-gas ratio decrease for smaller effective pore sizes, while the solution gas-oil ratio increases.

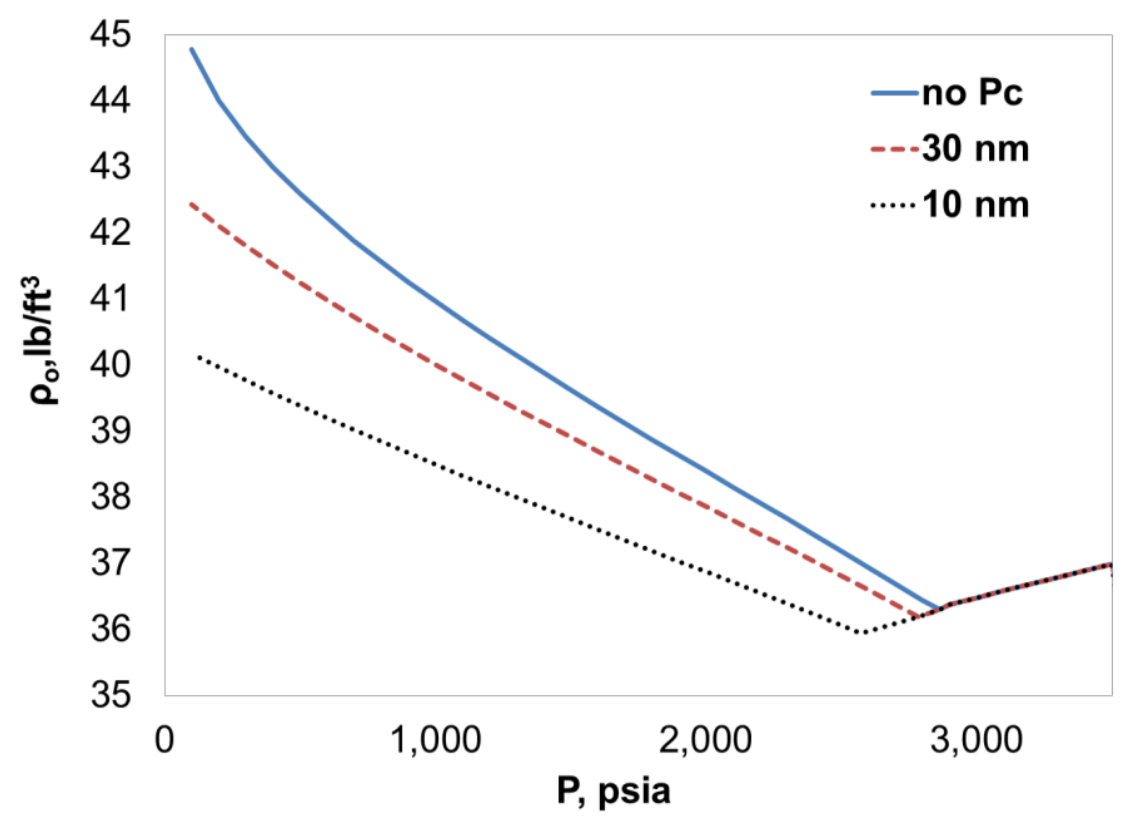

Figure 2- Oil density change with oil pressure and pore radius

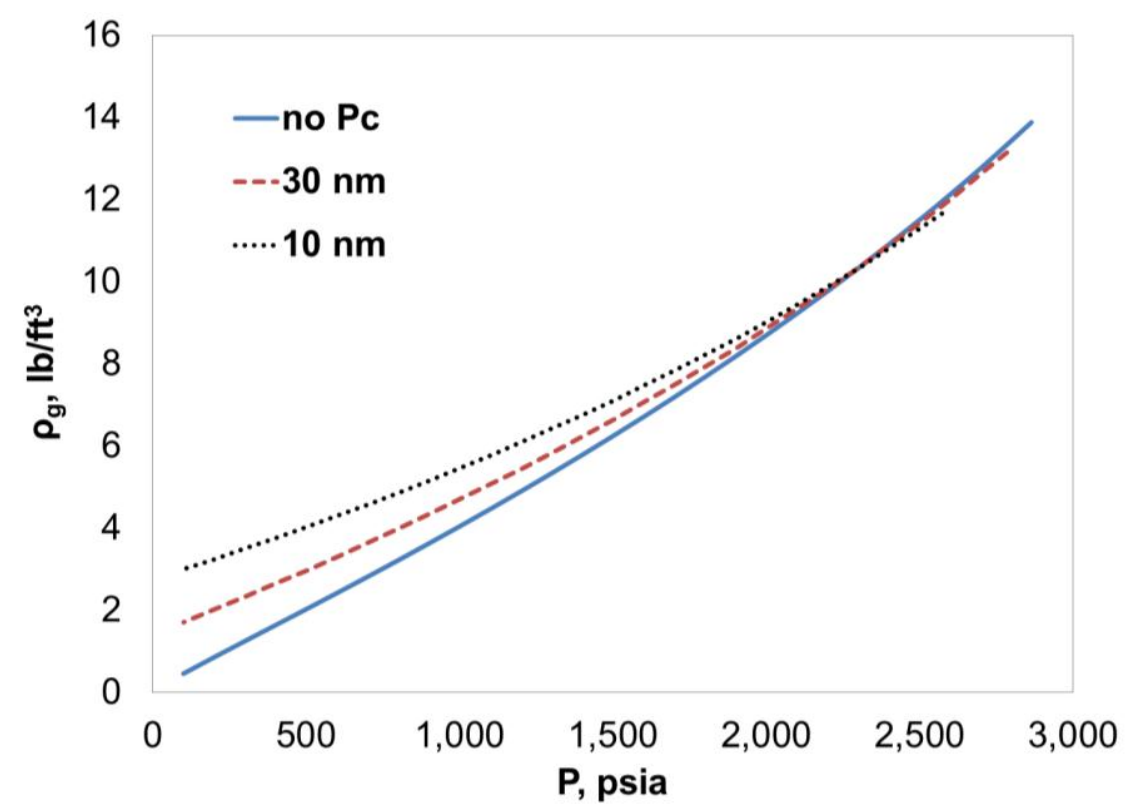

Figure 3- Gas density change with oil pressure and pore radius 


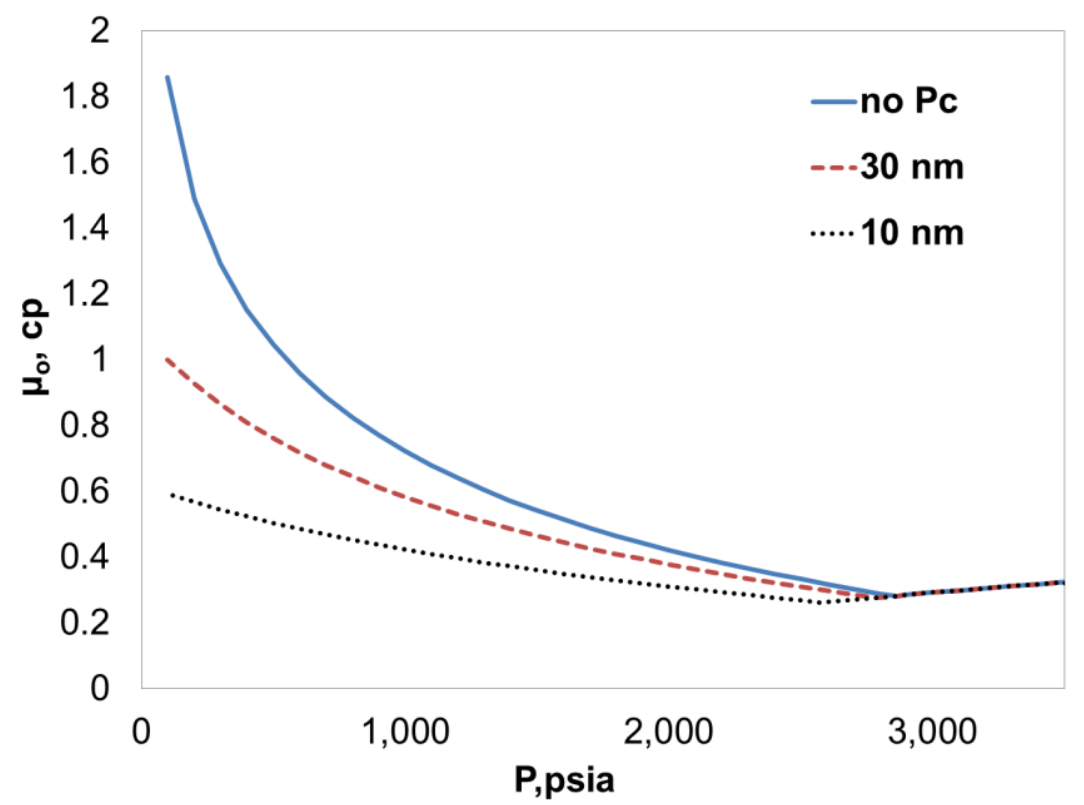

Figure 4- Oil viscosity change with oil pressure and pore radius

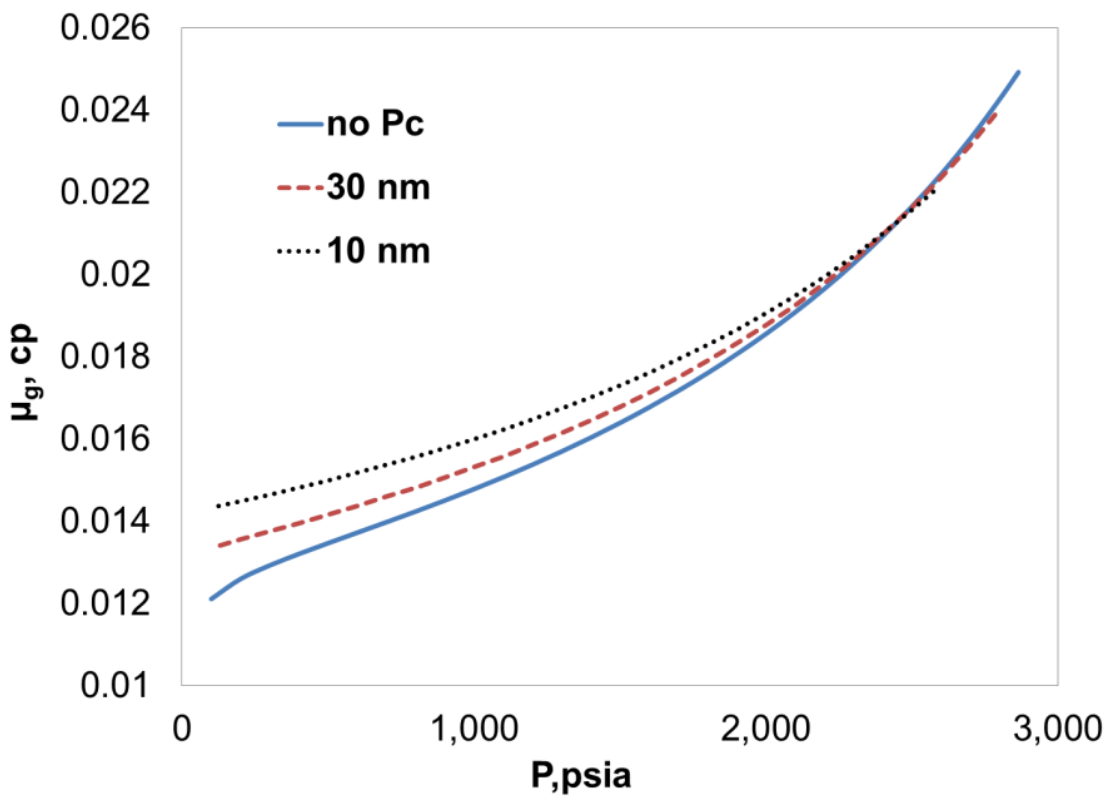

Figure 5- Gas viscosity change with oil pressure and pore radius 


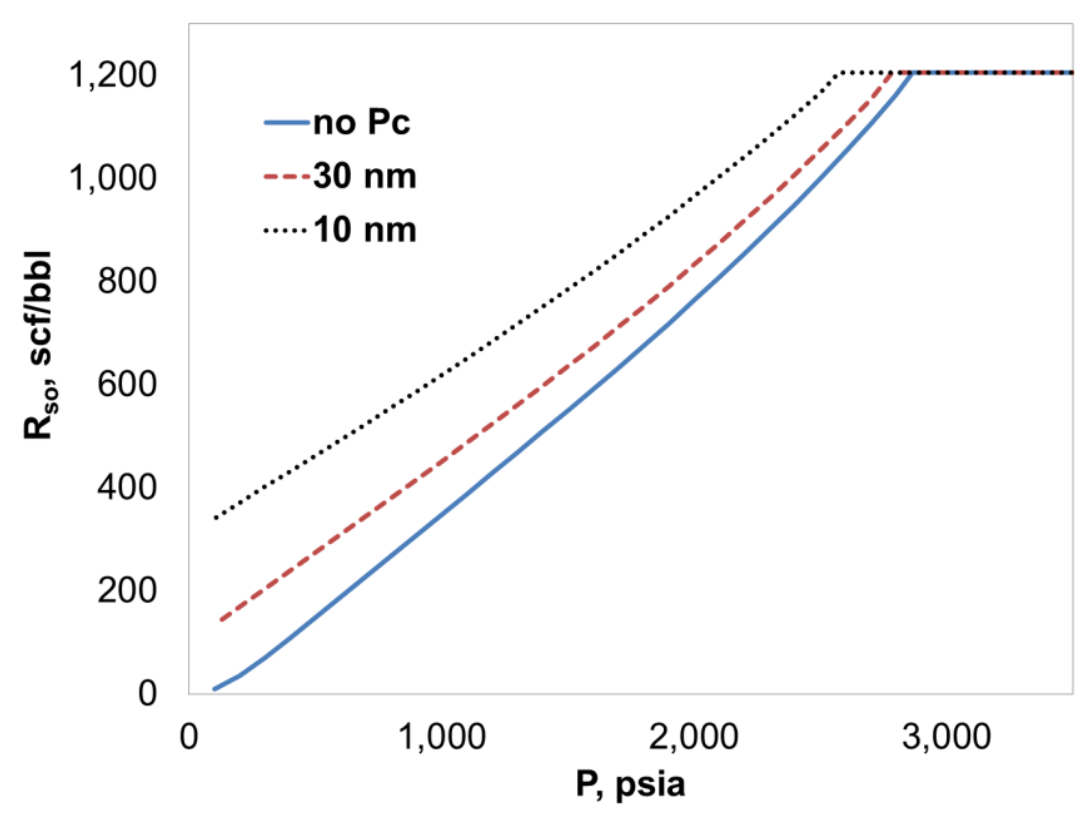

Figure 6- Solution gas-oil ratio change with oil pressure and pore radius

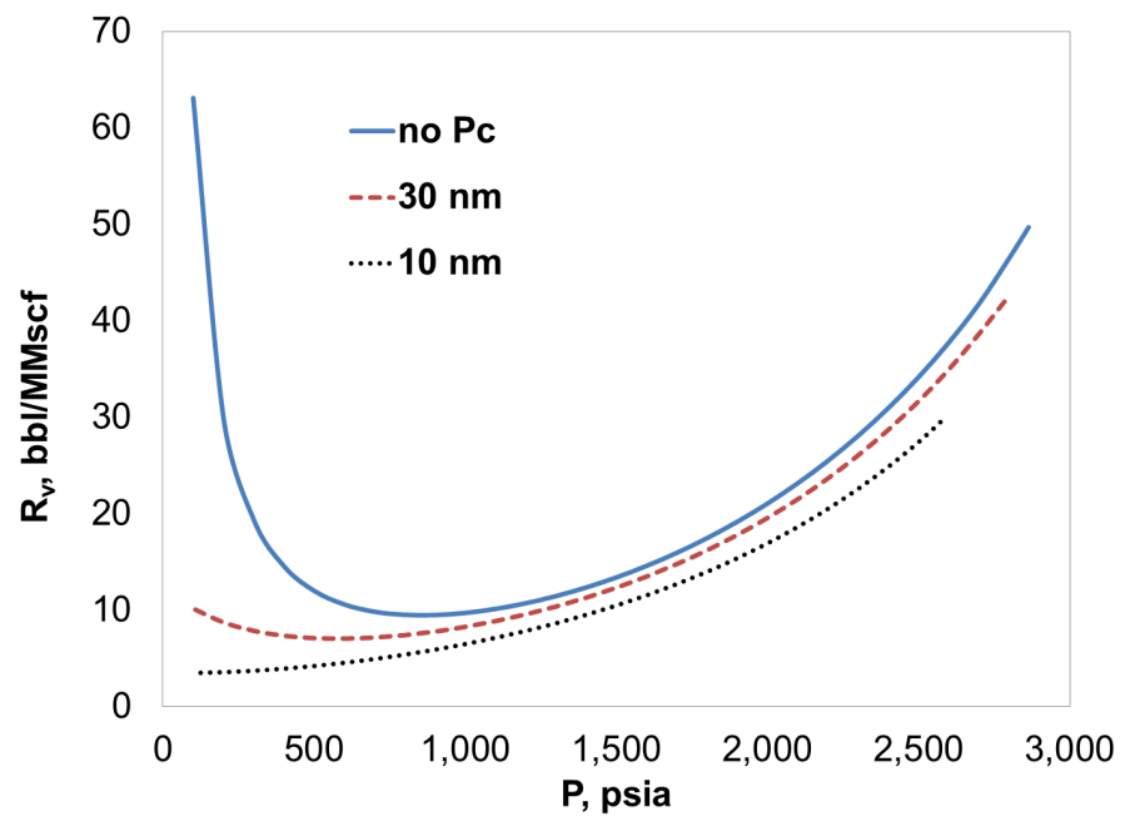

Figure 7- Volatile oil-gas ratio change with oil pressure and pore radius

As shown, oil viscosity, oil density and volatile oil-gas ratio decrease for smaller pore sizes, while the solution gas-oil ratio increases. Gas density and viscosity have no particular trend with pore size. For pressures greater than bubble-point pressure, the reservoir fluid is in the single-phase liquid region, where capillary pressure is not defined making oil properties constant with pore size. The change of fluid properties with pore curvature (inverse of pore radius) is almost linear as illustrated in Figure 8 for oil density. Therefore, linear interpolation of fluid properties with curvature is reasonably accurate. More black-oil data could be generated for different pore sizes if needed. 


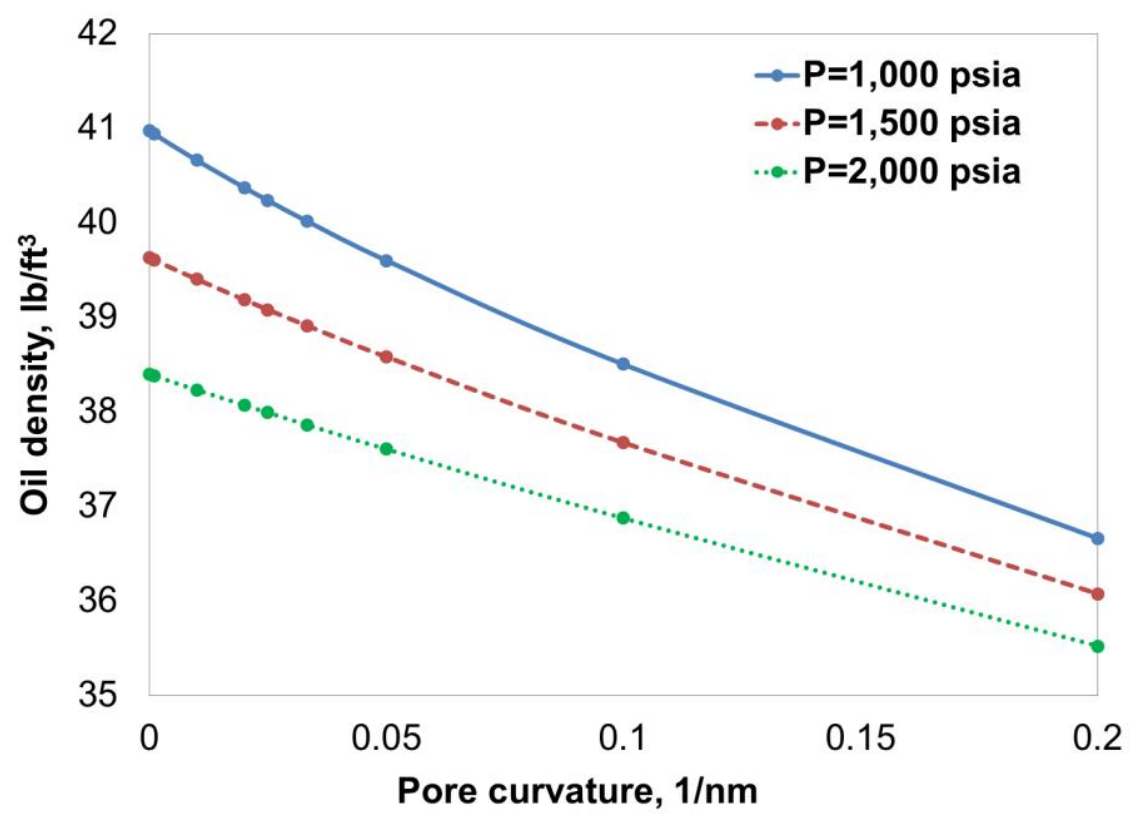

Figure 8- Bakken oil density versus pore curvature for three different pressures

Interfacial tension is calculated based on the Macleod and Sugden correlation (Macleod, 1923; Sugden, 1924; Pedersen and Christensen, 2007). As shown in Figure 9, interfacial tension changes with pressure, but does not change significantly with pore radius as long as pressure is relatively large and the pore size is greater than $10 \mathrm{~nm}$. Thus, IFT changes with pore size could be neglected at high producing pressures for this oil, but only for the calculation of gas pressure in the simulation. Interfacial tension is a function of pore size and is used for pre-calculating the black oil fluid properties with flash calculations. Because the interfacial tensions calculated from the correlation are smaller than measured values (Ayirala and Rao, 2006), we increased the IFTs by a constant factor of three.

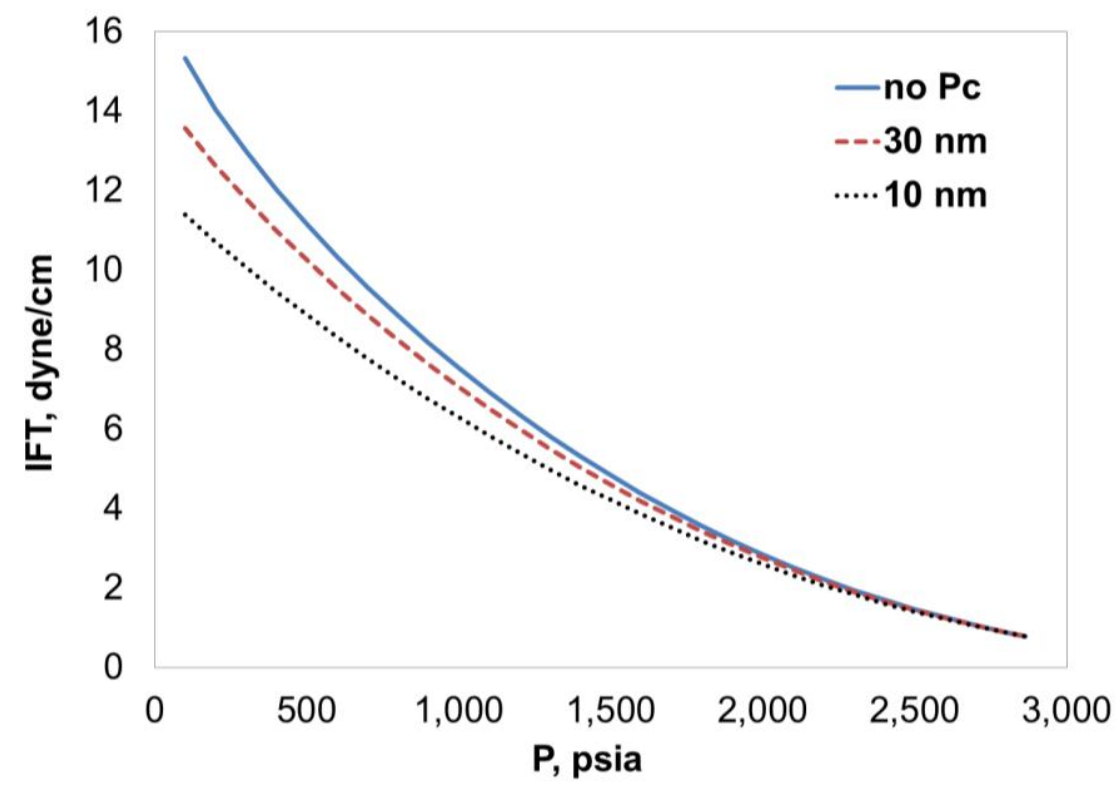

Figure 9- Gas-oil interfacial tension at three different pore sizes using the Macleod and Sugden correlation

\subsection{Three-Phase Capillary Pressure and Pore Size Distribution-Saturation Data}

One significant issue with ultra-low permeability rocks is the determination of capillary pressure. Example raw airmercury capillary pressure data and resulting pore-size distribution curves are shown in Figures $\mathbf{1 0}$ and $\mathbf{1 1}$ for Bakken core plugs. Because of the very small pore throats, mercury injection data should undergo several corrections including closure 
and fluid/cell compressibility (Comisky et al. 2007). The closure pressure is the pressure required for mercury to envelope the sample, but without intruding into pores. The reason for needing closure correction is because core plugs have external irregularities as a result of sample preparation (drill cutting and lost grains). Uncorrected data therefore will have a larger entry pressure than it should. Often, scanning electron microscopes or thin sections can help decide when closure has occurred by visually estimating the largest pore throat sizes present. For tight rocks, mercury injection pressures of several thousands of psi may be required to achieve significant mercury intrusion in some ultra-low permeability rocks (Sigal 2013). Mercury capillary pressure curves must also be converted to gas-oil and oil-water capillary pressures using interfacial tension and contact angle.

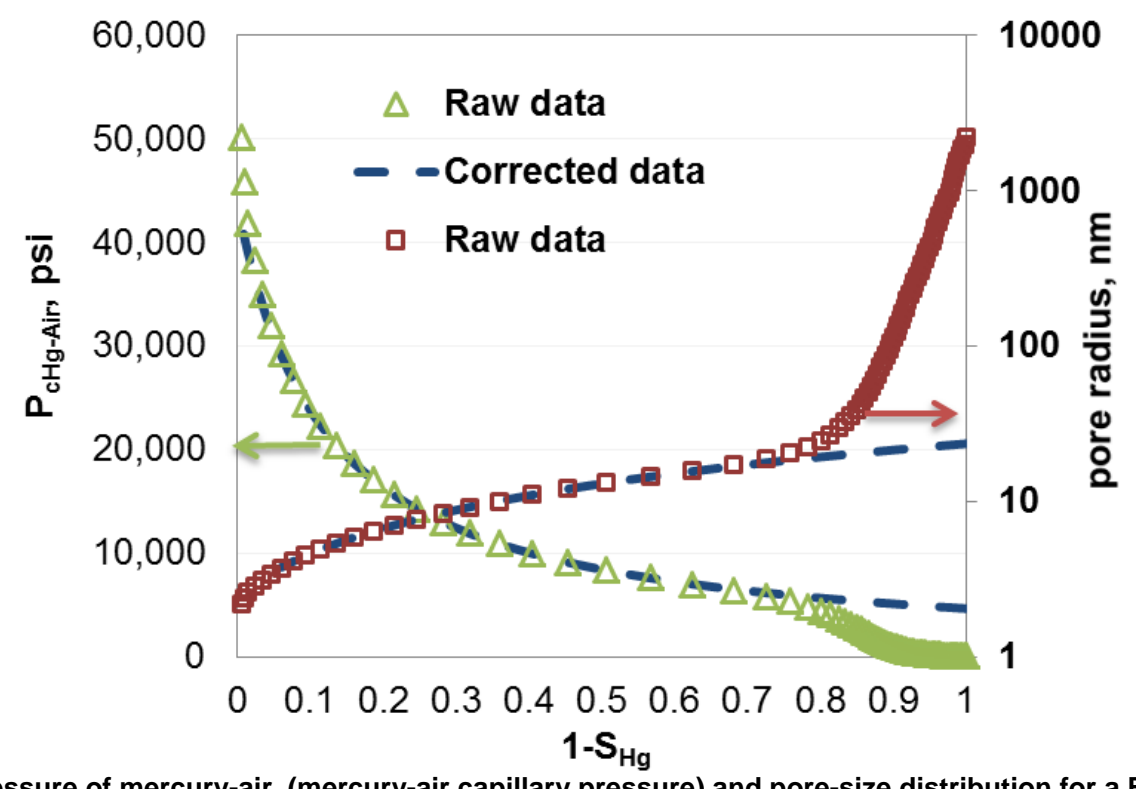

Figure 10- Injection pressure of mercury-air, (mercury-air capillary pressure) and pore-size distribution for a Bakken rock sample

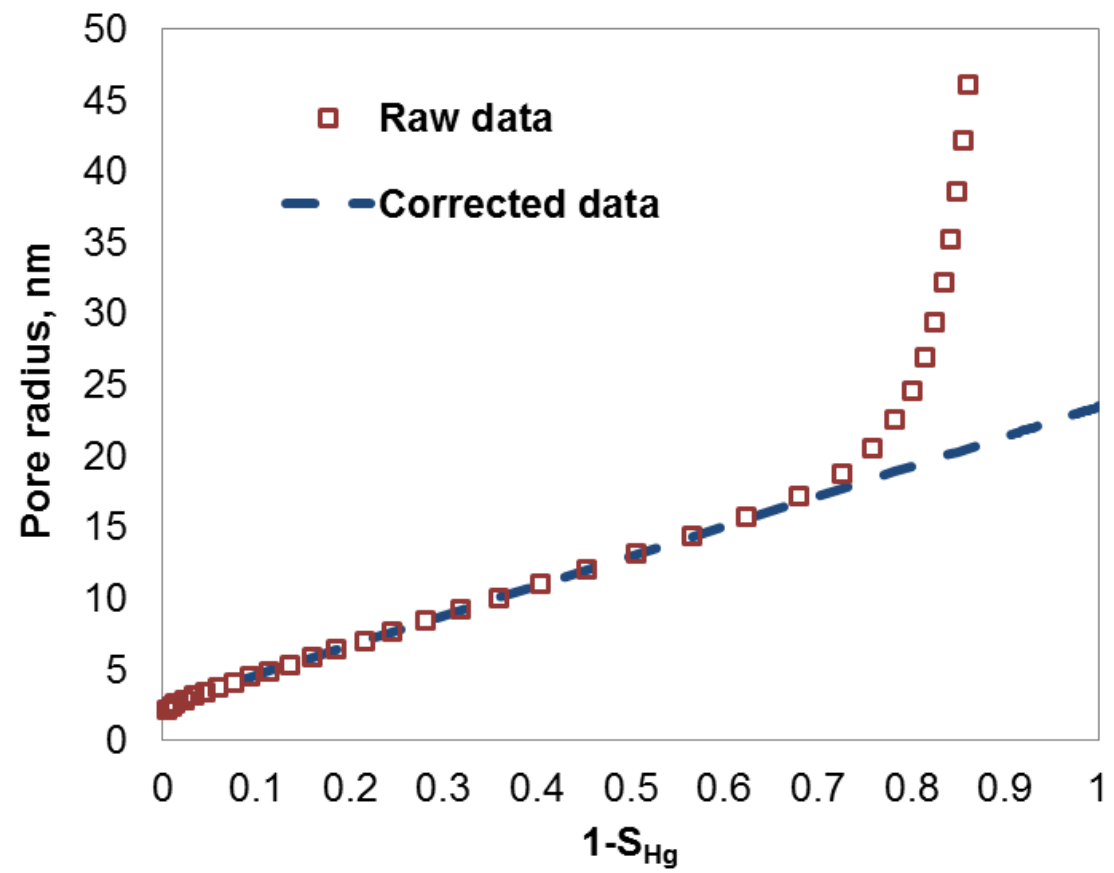

Figure 11- Pore size distribution versus the wetting phase saturation for a Bakken rock sample 


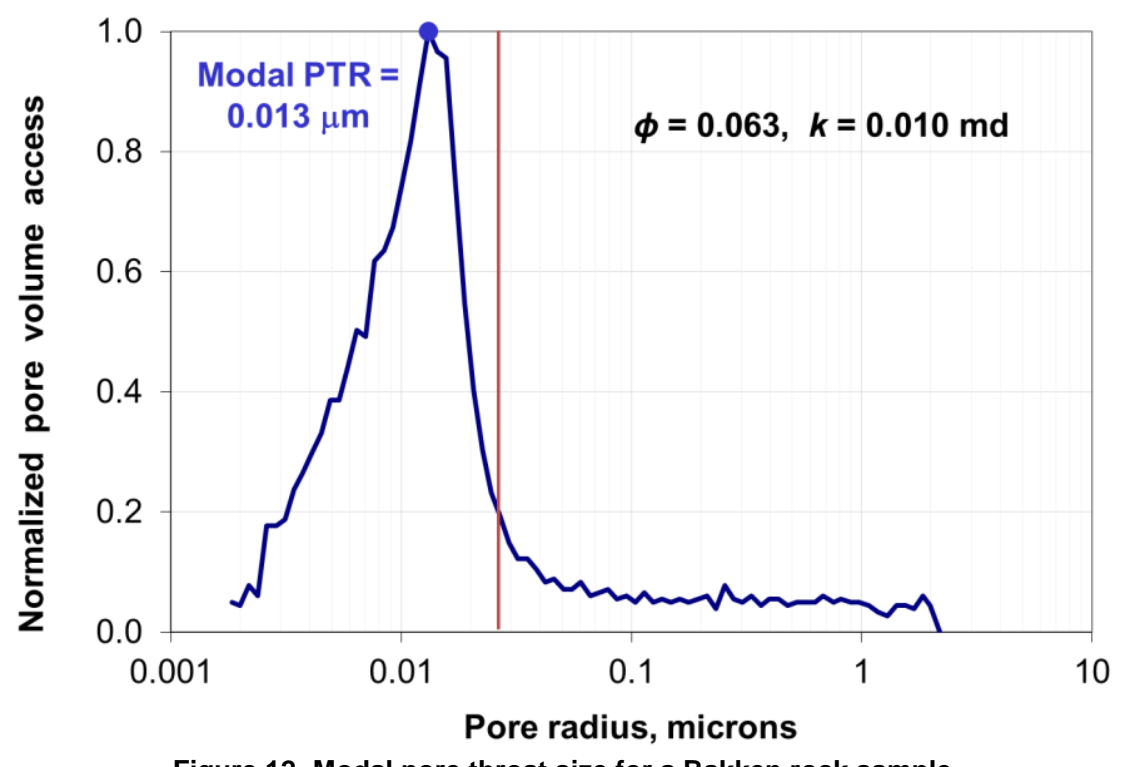

Figure 12- Modal pore throat size for a Bakken rock sample

The laboratory results of a Bakken core sample exhibit a modal pore throat radius of $13 \mathrm{~nm}$ (see Figure 12). We corrected the raw data assuming several thousands of psi were required for mercury injection to completely envelope the sample without entering the largest pore throat. This corresponds to pores smaller than $23 \mathrm{~nm}$ for the specific sample shown (left side of the red line in Figure 12). To correct for closure, a line was fit through the plateau region of the data. The extrapolation to zero mercury saturation of this line is the entry pressure of the core sample. Although this procedure is not very precise, we did not have further information to determine the entry pressure. The Leverett J-function (Leverett, 1941) was then determined from the air-mercury capillary pressure.

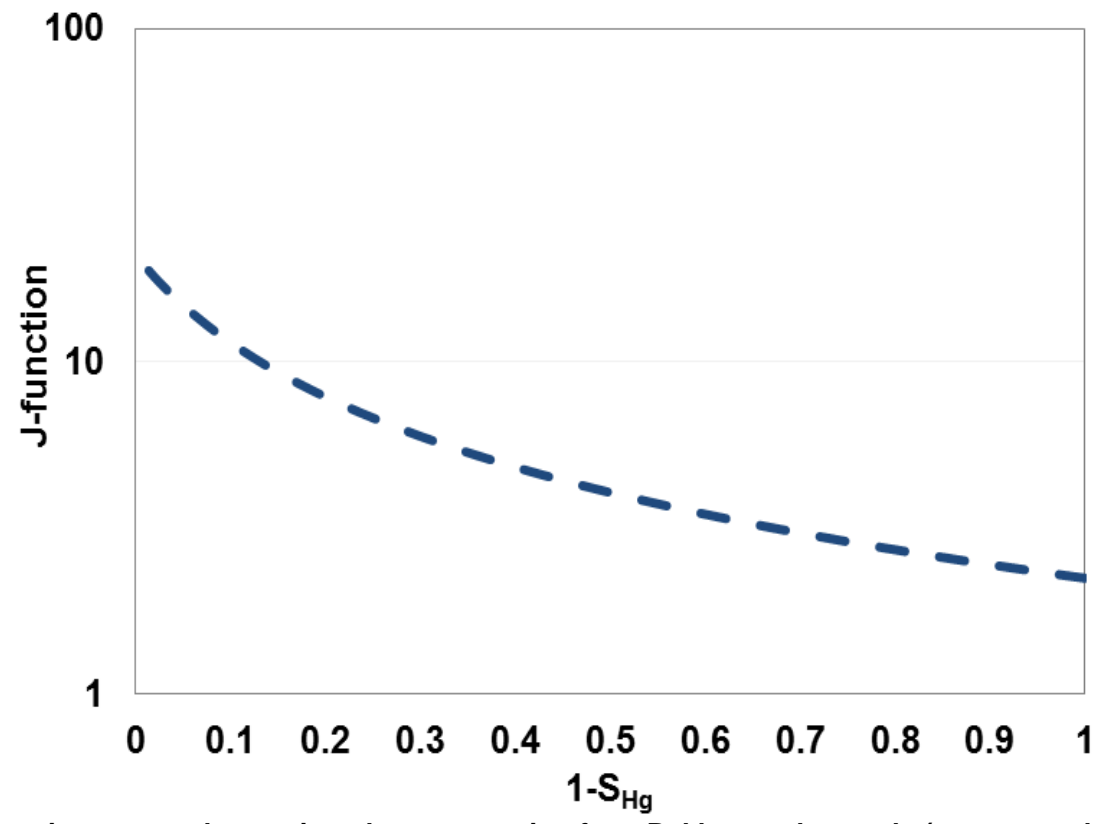

Figure 13- J-function versus the wetting phase saturation for a Bakken rock sample (same sample in Figure 10). 


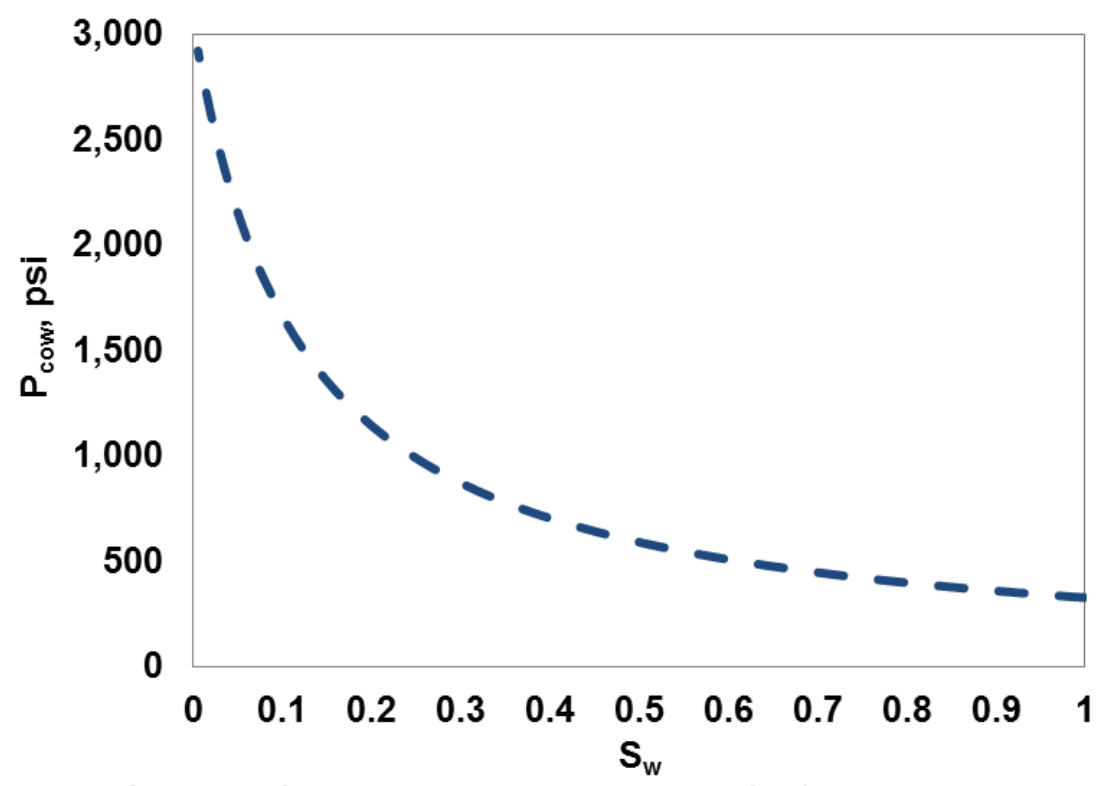

Figure 14- Oil-water capillary pressure versus water saturation for a Bakken rock sample

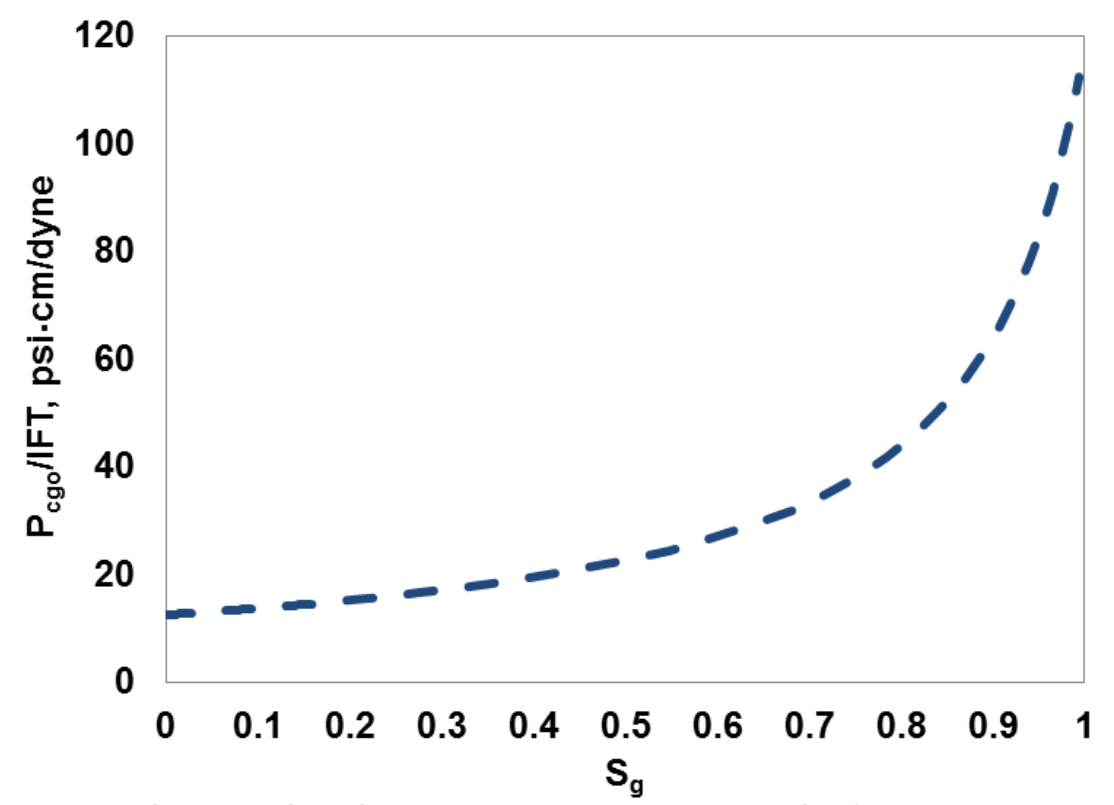

Figure 15- Normalized gas-oil capillary pressure versus gas saturation for a Bakken rock sample

The J-function is used to determine the gas-oil and oil-water capillary pressure for varying gas-oil interfacial tension, porosity, and permeability (see Figures 13-15). For gas-oil capillary pressure the wetting phase saturation is the liquid phase saturation, while for oil-water capillary pressure the wetting phase saturation is initially taken to be water for the Bakken reservoir. We used normalized gas-oil capillary pressure (capillary pressure divided by interfacial tension) because gas-oil interfacial tension is not fixed and can change with pressure. The normalized gas-oil capillary pressure is multiplied by the IFT to give gas-oil capillary pressure at any pressure and saturation during the simulation.

\subsection{Compositionally-Extended Black Oil Reservoir Simulation}

A black-oil model is a special case of compositional simulation where the components are oil, gas, and water, and the phases are oil (oleic), gas (vapor), and water (aqueous). Solving these component equations directly allows for switching from saturated to undersaturated conditions without the common discontinuity problem experienced in conventional black oil simulators. Fluid properties change with both pressure and saturation, which is accounted for in the non-linear system of equations. The principle unknowns are overall mass composition of gas component $Z_{g}$, oil pressure $P_{o}$ and water saturation $S_{w}$. These unknowns are determined using a fully-implicit scheme. We solve the following flow equations for oil and gas components: 
$\nabla \cdot\left(\sum_{j=1}^{N_{p}}\left(\omega_{i j} \rho_{j} \frac{k k_{r j}}{\mu_{j}} \nabla \cdot P_{j}-g \rho_{j} \nabla z\right)\right)+\sum_{j=1}^{N_{p}} M_{i j}=\frac{\partial}{\partial t}\left(\sum_{j=1}^{N_{p}} \phi S_{j} \rho_{j} \omega_{i j}\right)$,

where $\omega_{i j}$ is the mass fraction of component $i$ in phase $j$; and for the water component:

$$
\nabla \cdot\left[\frac{k k_{r w}}{B_{w} \mu_{w}}\left(\nabla P_{w}-g \rho_{w} \nabla z\right)\right]-q_{w}=\frac{\partial}{\partial t}\left(\frac{\phi S_{w}}{B_{w}}\right) \text {. }
$$

No oil and gas exists in the aqueous phase, but we do allow for dissolved gas in the oleic phase and volatilized oil in the vapor phase through the solution gas-oil ratio, $R_{s o}$, and the volatile oil-gas ratio $R_{v}$.

The compositional approach uses $K$-values that are functions of the black-oil properties. The component $K$-values between the vapor and oleic phases are explicitly calculated using Eq. (5) and Eq. (6) and the prior tabulated fluid properties as described in the previous section. That is,

$$
\begin{aligned}
& \frac{\omega_{o g}}{\omega_{g g}}=5.615 \times 10^{-6} \cdot \frac{\rho_{o, s c}\left(l b / f t^{3}\right)}{\rho_{g, s c}\left(l b / f t^{3}\right)} \cdot R_{v}(S T B / M M S C F) \\
& \frac{\omega_{g o}}{\omega_{o o}}=178.094 \cdot \frac{\rho_{g, s c}\left(l b / f t^{3}\right)}{\rho_{o, s c}\left(l b / f t^{3}\right)} \cdot R_{s o}(M S C F / S T B) .
\end{aligned}
$$

where,

$$
K_{g}=\frac{\omega_{g g}}{\omega_{g o}} \quad \text { and } \quad K_{o}=\frac{\omega_{o g}}{\omega_{o o}}
$$

There are a total of four equations: Eqs. (5) and (6) and two equations where mass fractions of a given phase sum to one. Thus, the mass phase fractions are determined without iteration.

The black oil properties are determined from linear interpolation of the pre-tabulated values based on the pore radius that the gas-oil interface occupies at a particular value of gas saturation. This pore size is termed the effective pore size in this paper. At every time step, gas saturation is calculated for each grid block and the corresponding effective pore radius is specified. The gas phase is assumed the nonwetting phase so that gas-oil capillary pressure is a function only of gas saturation. As gas saturation increases, the effective pore size is reduced.

By use of an extended black oil reservoir simulator, the oil pressure, overall gas composition and water saturation can be solved first and oil and gas saturations subsequently calculated. The corresponding pore throat size can be estimated from the J-function plot and the mercury pore-size distribution of the Bakken rock. Gas-oil capillary pressure is proportional to the pressure-dependent IFT and saturation-dependent J-function, so gas-oil capillary pressure is a function of both pressure and saturation. Black oil fluid properties are calculated by linear interpolation of pore curvature (one over pore radius) at any effective pore radius which changes with saturation, so these fluid properties change with both pressure and saturation. The algorithm that we follow during each time step is illustrated in Figure 1. The principal unknowns are oil phase pressure, gas overall composition and water saturation. Knowing the values of the principal unknowns from the previous time step, gas and oil compositions are calculated using Eqs. 5, 6 and 7. After calculating oil and gas saturation, the corresponding effective pore radius is computed. Fluid properties are functions of both pressure and effective pore radius so they should be updated after calculating saturations. This algorithm proceeds iteratively until convergence is achieved.

\section{Simulation Results and Discussion}

We first compare the results of the compositionally-extended black oil model to the results of a fully-compositional model to ensure that our model captures the required complexities due to capillary pressure and pore-size distribution accurately. The importance of pore-size distribution is demonstrated using a single fixed pore size. In the last section, we examine the effect of reservoir initial pressure on production increase when capillary pressure effects on phase behavior are included. 


\subsection{Case1: Comparison of the Compositionally-Extended Black Oil Model with Fully-Compositional Simulation}

We first compare the results of the compositionally-extended black oil model to the results of a fully-compositional model to ensure that our model captures the required complexities due to capillary pressure and pore-size distribution accurately. The compositional model used in this study follows the formulation described in Coats (1980) where natural variables are selected as principal unknowns and fluid transport and phase behavior are solved simultaneously. The principal unknowns in this formulation are oil phase pressure $\left(P_{o}\right)$, liquid compositions $\left(x_{i}\right.$, for $\left.i=1,2,3, \ldots N_{C}-1\right)$, vapor compositions $\left(y_{i}\right.$, for $i=$ $\left.1,2,3, \ldots N_{C^{-1}}\right)$, liquid saturation $\left(S_{o}\right)$, and vapor saturation $\left(S_{g}\right)$. To account for the effect of capillary pressure on phase behavior, a modified negative flash calculation is implemented into model. We do not include fractures here, but for simplicity use increased matrix permeability to account for the effect of intensely spaced fractures on flow. Thus, the reservoir model is a single porosity system. Relative permeability curves are adapted from Shoaib and Hoffman (2009) and are shown in Figure 16. The reservoir properties are given in Table 1. The reservoir is a 2-D rectangular domain with 25 (5 by 5) grid blocks. Initial reservoir pressure is 4,200 psia. The production well is at the center and the well bottom hole pressure is specified to be 100 psia to give a large pressure variation in the results. Peaceman's model for centered vertical wells (Peaceman, 1978) is used for the well grid block. The initial water saturation is 0.25 , while residual water saturation is 0.2. The critical gas saturation, the minimum gas saturation at which the vapor starts to flow, can be as high as 0.4. Both models include the effect of capillary pressure on phase behavior in a rigorous way as has been described previously (Nojabaei et al. 2013).
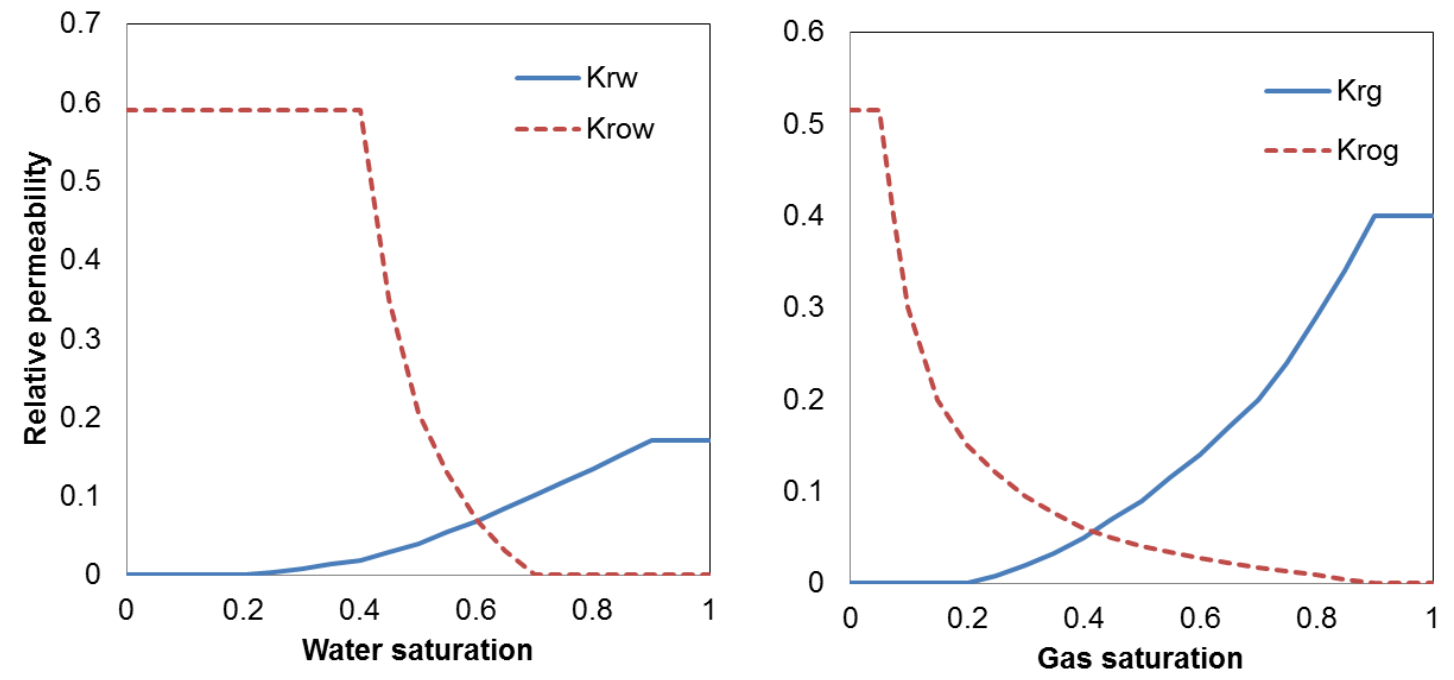

Figure 16- Relative permeability curves for case 1

Table 1- Reservoir and fluid properties for case 1

\begin{tabular}{lc}
\hline Reservoir size & $1500 \mathrm{ft} \times 1500 \mathrm{ft}$ \\
\hline Uniform grid block size & $300 \mathrm{ft} \times 300 \mathrm{ft}$ \\
\hline Enhanced permeability & $10 \mathrm{md}$ \\
\hline Enhanced porosity & $4.4 \%$ \\
\hline Reservoir thickness & $10 \mathrm{ft}$ \\
\hline Fluid type & Bakken fluid \\
\hline Temperature & $240^{\circ} \mathrm{F}$ \\
\hline
\end{tabular}

The results from both simulators agree well for the cases considered, especially considering that the fully compositional model uses eight components to describe the production process, while the black-oil model uses only two hydrocarbon components. Capillary pressure is always considered in the flow calculations, but is not always accounted for in the phase 
behaviour calculations as indicated. The bubble-point pressure is reduced from about 2,870 psia to 2,770 psia owing to capillary pressure for both models as shown in Figure 17. The bubble-point pressure is reached later for the case with capillary pressure included for both the extended black oil and compositional models.

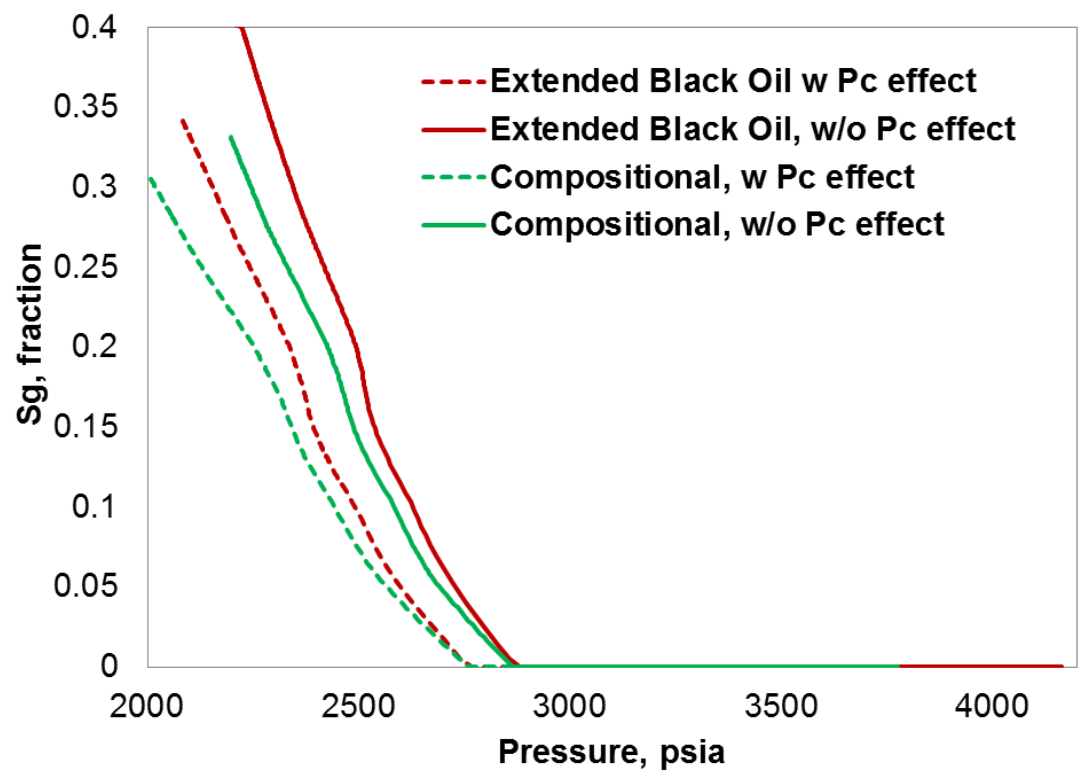

Figure 17- Comparison of Well block gas saturations versus well block pressures for extended black oil and compositional simulations

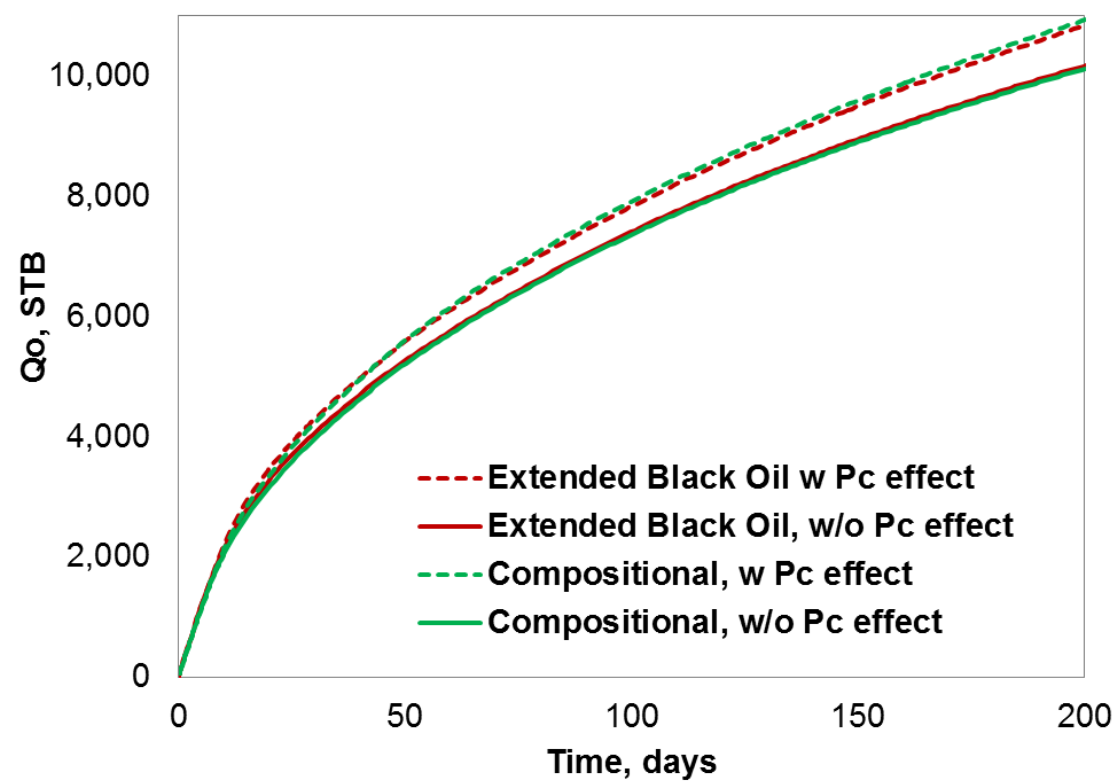

Figure 18- Comparison of cumulative oil production for extended black oil and compositional simulations 


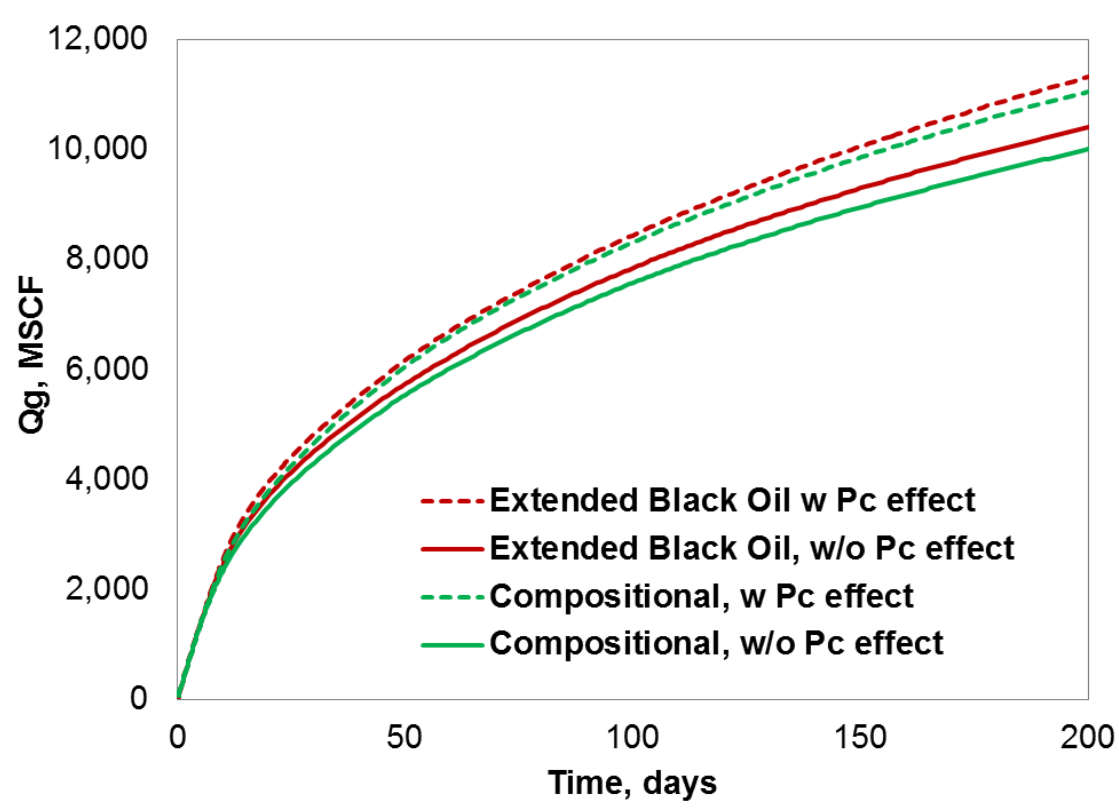

Figure 19- Comparison of cumulative gas production for extended black oil and compositional simulations

The cumulative productions are also close for both the extended black oil and the compositional simulation results (Figure 18 and 19). Further, the gas and oil cumulative recoveries show the same trends and are greater when capillary pressure effects on phase behavior are included. The extended black oil model gives a $7.4 \%$ increase in cumulative oil production and a $9.9 \%$ increase in gas production, while the fully-compositional simulation gives a $7.9 \%$ increase in oil recovery and a $10.5 \%$ increase in gas recovery. These results for this one case study demonstrate the reliability of using an extended black oil model to simulate the effects of capillary pressure on phase behavior in tight formations based on precalculated fluid properties from a cubic equation-of-state.

\subsection{Case2: Pore size distribution versus a constant pore size}

We next demonstrate the potential importance of using pore-size distribution instead of a single fixed pore size to model the effect of capillary pressure on phase behavior. The production results of three cases are compared. Capillary pressure does not affect fluid properties in the first case. For the second case capillary pressure affects the fluid properties and is calculated based on an average pore size taken to be the modal pore radius measured for the Bakken sample. In the third case, the effect of capillary pressure including the actual pore-size distribution (PSD) is modelled. The pore-size distribution is a function of the gas phase saturation for the last case. 


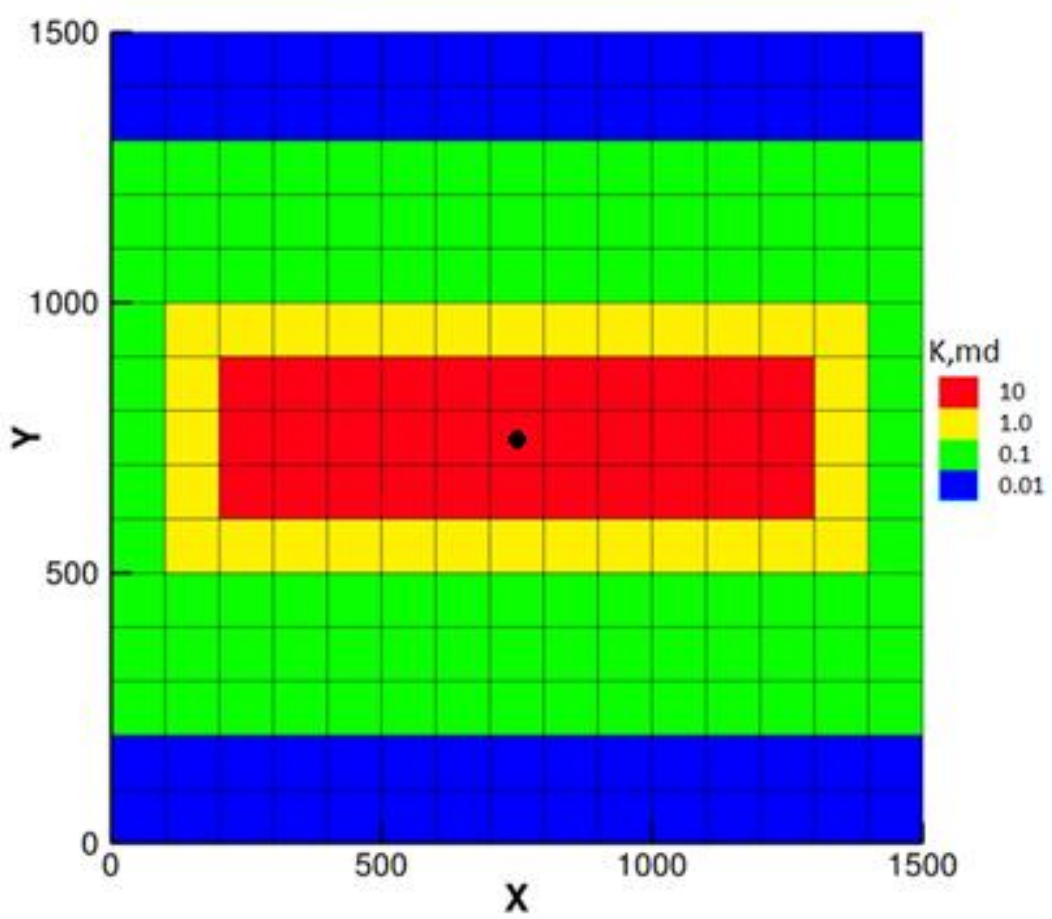

Figure 20- Reservoir permeability map for case 2

Here, we use a composite reservoir model with various reservoir properties and a larger number of grid blocks (225 grid blocks). Reservoir permeability is not uniform and permeability distribution is shown in Figure 20. Reservoir permeability is larger around the well and the imaginary fracture to account for stimulated reservoir volume. Other reservoir and fluid properties are shown in Table 2.

Table 2- Reservoir and fluid properties for case 2

\begin{tabular}{lc}
\hline Reservoir size, 2D & $1500 \mathrm{ft} \times 1500 \mathrm{ft}$ \\
\hline Uniform grid block size & $100 \mathrm{ft} \times 100 \mathrm{ft}$ \\
\hline porosity & $6 \%$ \\
\hline Reservoir thickness & $10 \mathrm{ft}$ \\
\hline Fluid type & Bakken fluid \\
\hline Temperature & $240^{\circ} \mathrm{F}$ \\
\hline
\end{tabular}



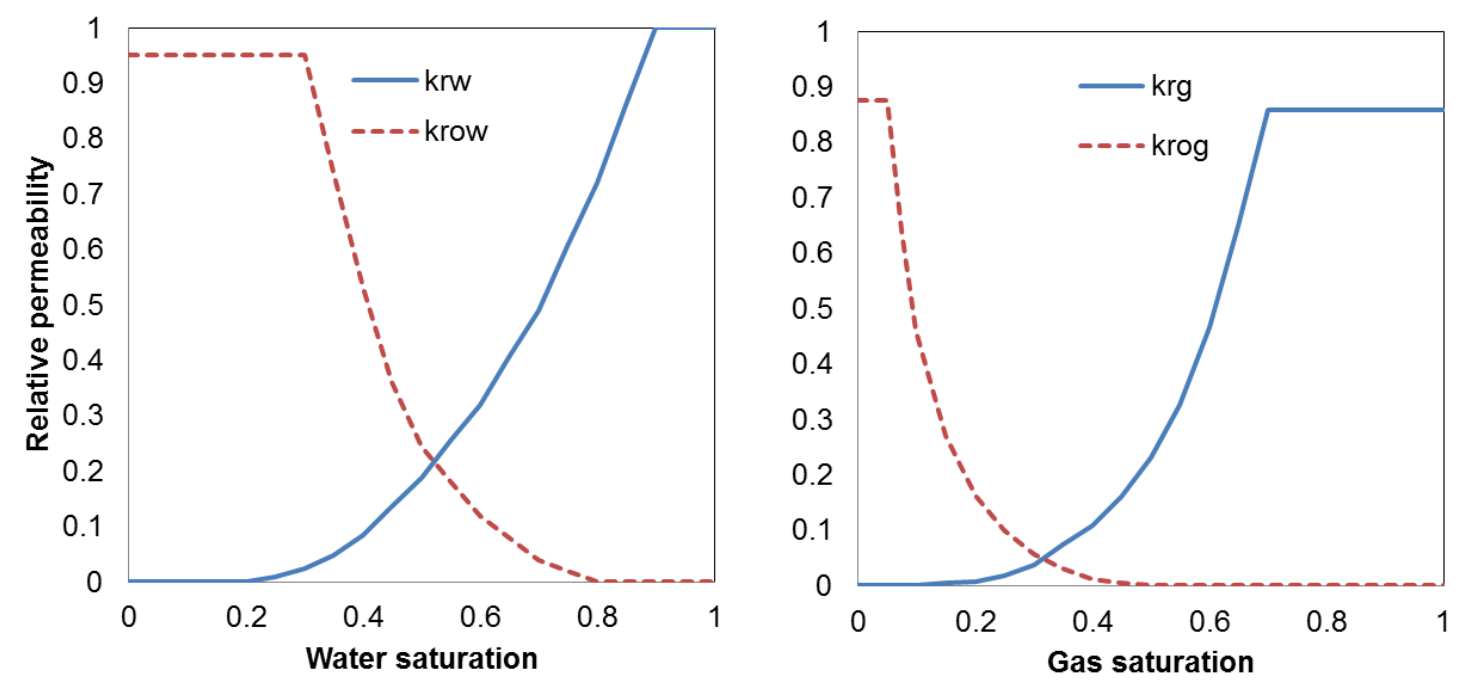

Figure 21- Relative permeability curves for case 2, adopted from Yu et al. (2014)

Relative permeability curves for the Bakken reservoir are adopted from Yu et al. (2014) and are shown in Figure 21. Reservoir initial pressure is 5500 psia and well pressure is set at 500 psia. Simulations are performed for 700 days. For all three cases, oil-water and gas-oil capillary pressure are included in the flow model.

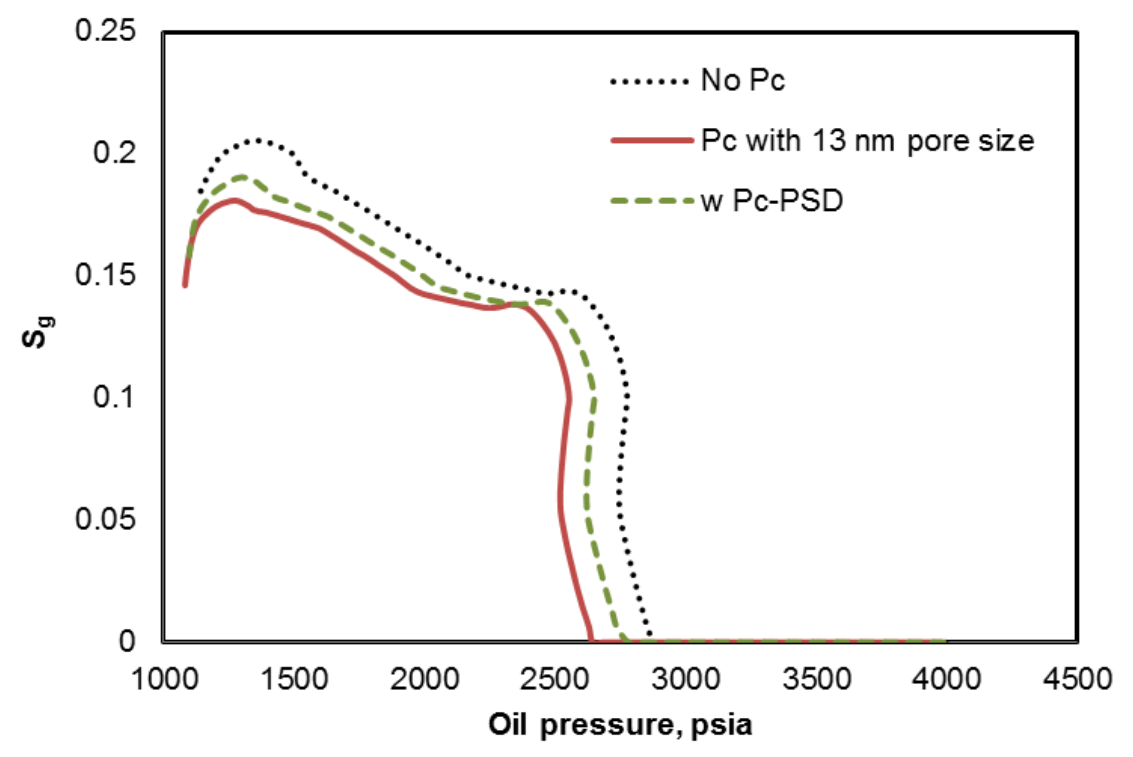

Figure 22- Well block gas saturations versus well block pressures for case 2 


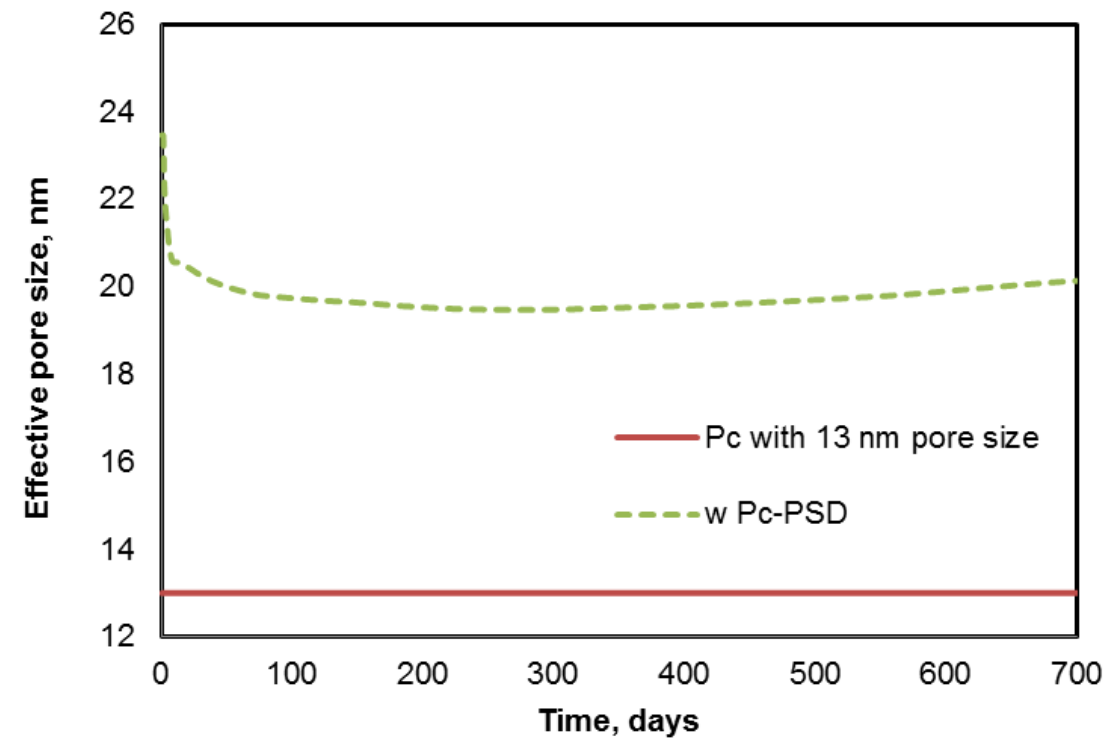

Figure 23- Effective well block pore radius versus time for case 2

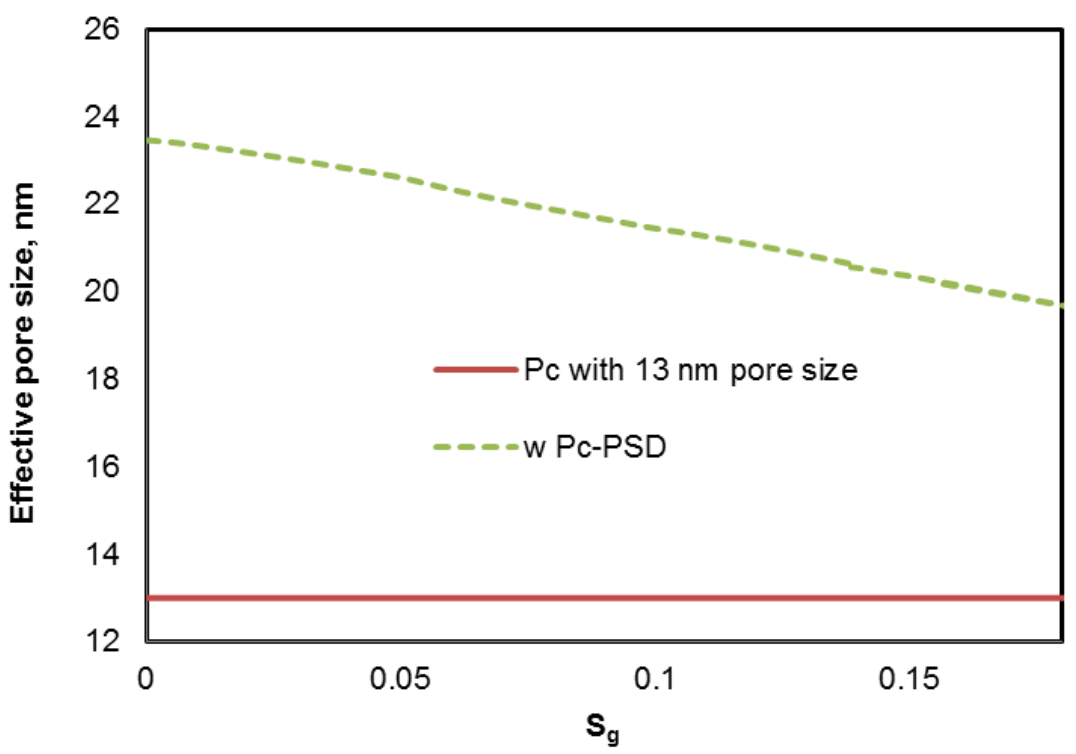

Figure 24- Effective well block pore radius versus gas saturation for case 2

Figures 22 and $\mathbf{2 3}$ give the gas saturations and effective pore sizes at the well grid block. The effective pore size is a function of gas saturation for PSD and is approximately $24 \mathrm{~nm}$ when gas saturation is zero. The effective pore size decreases when gas saturation increases. The size decreases to about $19 \mathrm{~nm}$ after 700 days while the modal pore radius is fixed at $13 \mathrm{~nm}$ as shown in Figure 24. For smaller pore sizes, capillary pressure is larger resulting in an increased effect of capillary pressure at late time. Figure 22 also shows that bubble-point pressure is smaller for the fixed pore size case compared to the PSD case. Because gas saturation is zero at the bubble-point, the effective pore size is about $24 \mathrm{~nm}$ for the PSD case compared to $13 \mathrm{~nm}$ for the fixed modal pore size case. As a result, the bubble-point pressure is reduced more for the fixed pore size case. The effective pore size does not become smaller than the modal pore size in this case, but if we allow for larger gas saturations, the effective pore size could decrease to less than $13 \mathrm{~nm}$. 


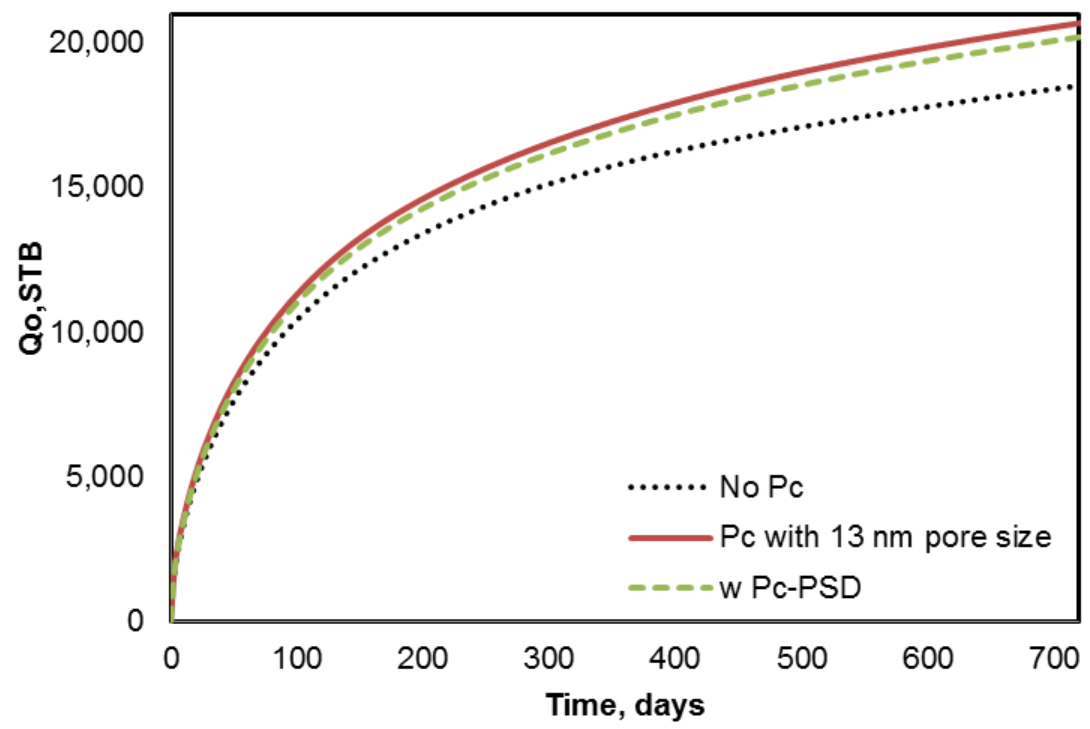

Figure 25- Comparison of cumulative oil production for cases using pore-size distribution and a fixed average pore size

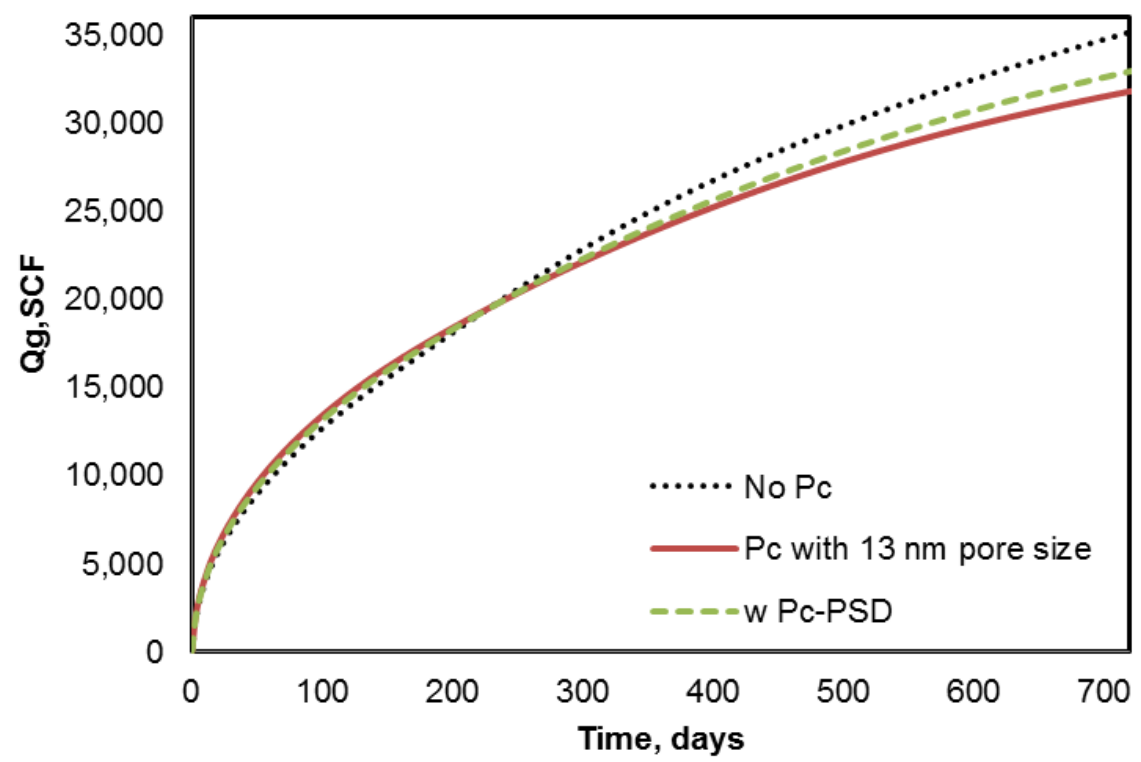

Figure 26- Comparison of cumulative gas production for cases using the pore-size distribution and a fixed average pore size

Figures 25 and 26 show that the choice of the pore size can have an impact on oil recovery. For example, there is an increase of $11.6 \%$ in oil production when the pore size is averaged at the model value of $13 \mathrm{~nm}$, while the change in oil and gas production is $9.1 \%$ with the PSD approach. The difference is relatively small in this case, but its importance depends on many factors including the shape of the pore-size distribution and gas saturation.

Figure 26 also shows that cumulative production of gas increases owing to the effect of capillary pressure in early time. At late time, the effect of high capillary pressure decreases cumulative gas production. At early time, gas does not flow since gas saturation is smaller than the critical gas saturation. The produced gas comes from the oil as solution gas so the increase in gas production is related to the increase in oil production. As gas saturation increases beyond the critical gas saturation, gas flows and the change in gas production due to capillary pressure becomes less dependent on oil production. We did not have this observation for case 1 as critical gas saturation was very high in that case and the production results were reported for a shorter period of time. 


\subsection{Case 3: Effect of capillary pressure on recovery and original oil in place}

In this example, we show how high gas-oil capillary pressure significantly influences the original oil in place (OOIP) and recoveries, and how the differences depend on reservoir initial pressure. The example is a square reservoir with a horizontal producer at the center of the reservoir as shown in Figure 27.

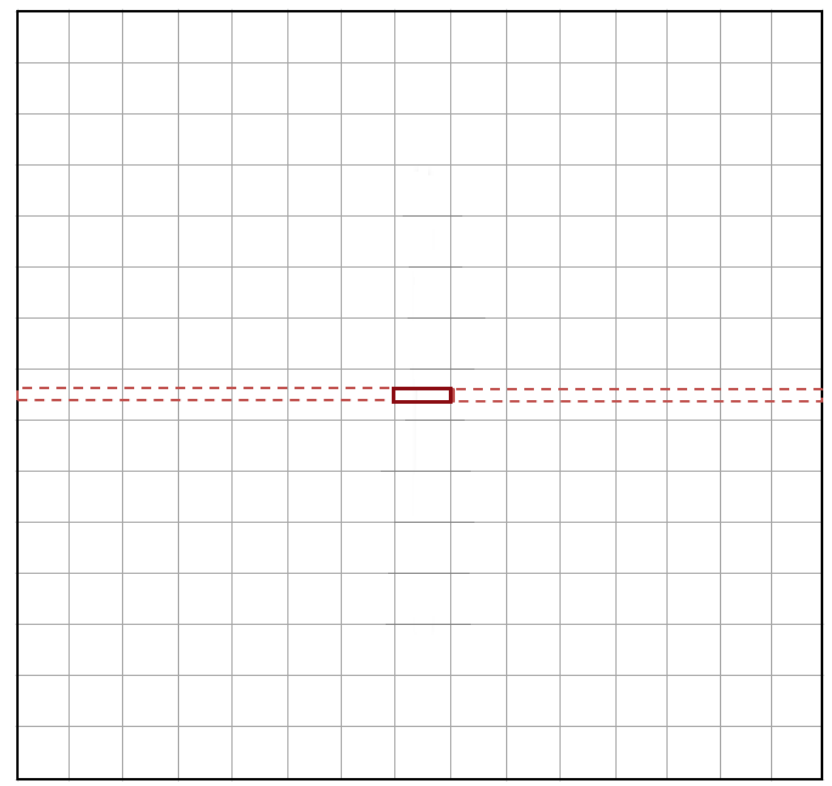

Figure 27- Schematic of the reservoir with a horizontal well for case 3

Table 3- Reservoir and fluid properties for case 3

\begin{tabular}{lc}
\hline Reservoir size, 2D & $750 f t \times 750 f t$ \\
\hline Uniform matrix grid block size & $50 f t \times 50 f t$ \\
\hline Matrix permeability & $2 \mathrm{md}$ \\
\hline Matrix porosity & $6 \%$ \\
\hline Reservoir thickness & $10 \mathrm{ft}$ \\
\hline Fluid type & Bakken fluid \\
\hline
\end{tabular}

Table 3 summarizes reservoir properties used. The reservoir temperature is $240^{\circ} \mathrm{F}$ and the reservoir fluid is Bakken oil with a bubble point of 2860 psia when capillary pressure is zero. Initial water saturation in the matrix is 0.25 , while the well pressure is held at 500 psia. The relative permeability curves are the same as those shown in Figure 21. 


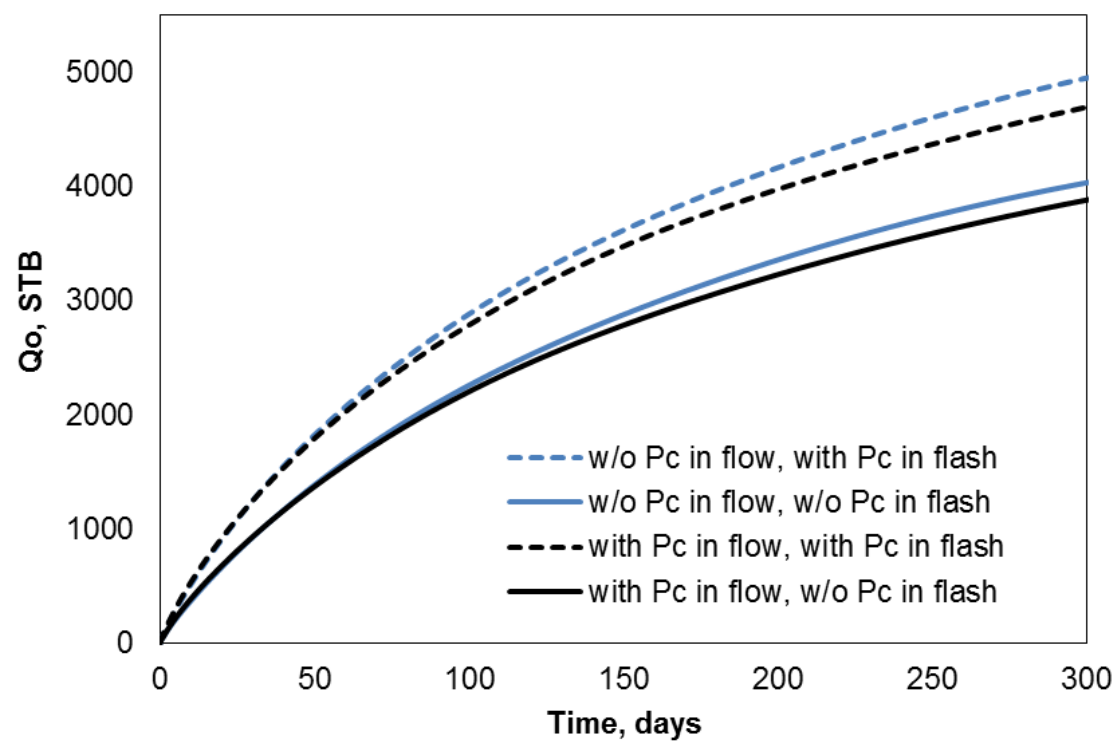

Figure 28- Cumulative oil production for different capillary pressure conditions for $\mathbf{P}_{\text {initial }}=2700$ psia

Figure 28 shows the recoveries for simulations where the initial pressure is 2700 psia and capillary pressure is included or neglected in the flow calculations. Pressure gradients are very large near the sandface when capillary pressure is included. This causes the water pressure at the sandface to decrease below the production well pressure, which could potentially lead to instabilities in the simulation. Depending on the reservoir pressure, the water pressure could even become negative. More grid blocks near the producer stabilizes the well block pressure resulting in more accurate simulations, but at the expense of computational time. The results in Figure 28 show that for the simulations examined here inclusion of capillary pressure in flow generally increases production but this effect is smaller than when the flash is impacted by capillary pressure. Therefore, we have neglected capillary pressures (both gas-oil and water-oil) on flow for the primary recovery simulations presented here (case 3). Certainly, the impact of large pressure gradients near the well could be very important if fluids are injected, depending on the wettability.

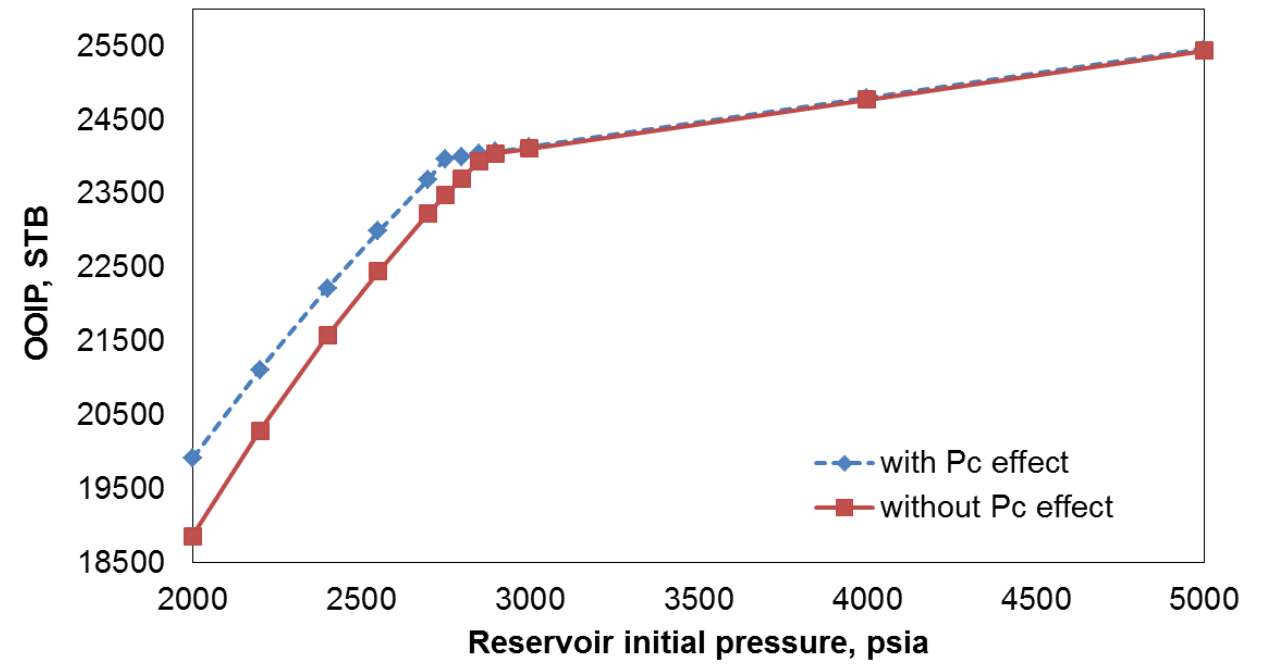

Figure 29- Original oil in place as a function of reservoir initial pressure with and without capillary pressure effect 


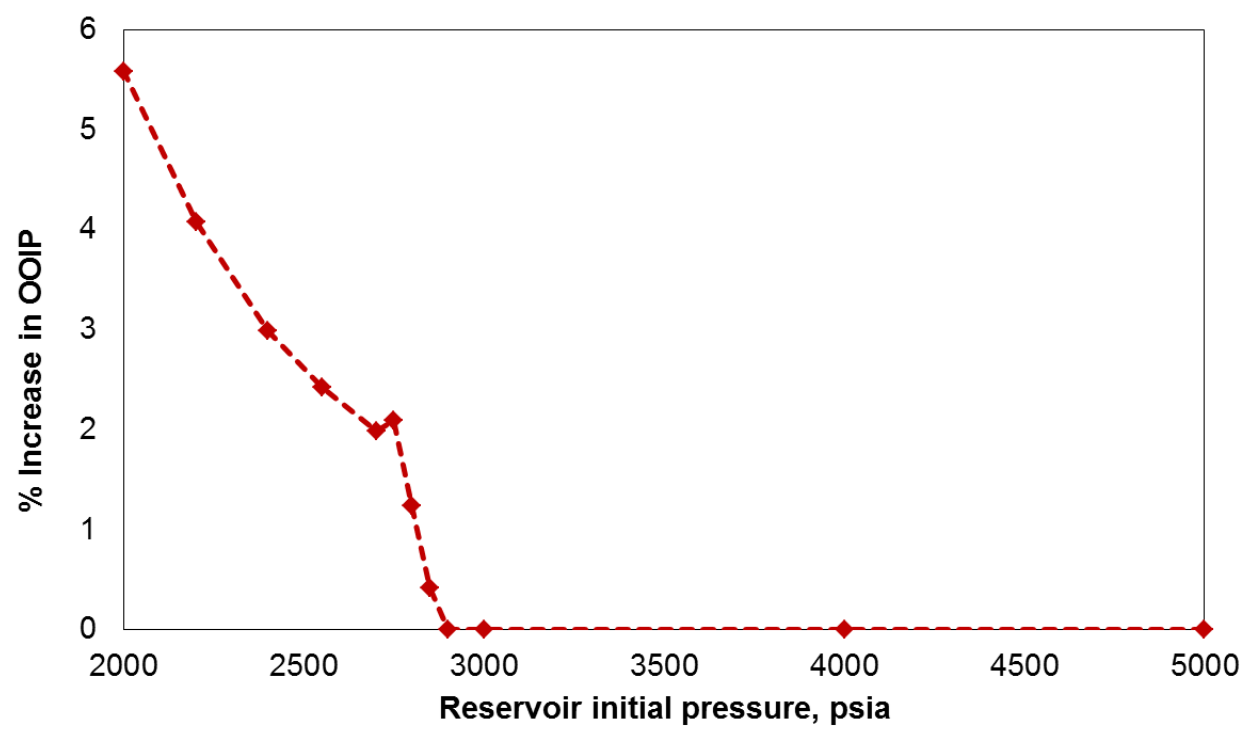

Figure 30- Percentage increase in original oil in place owing to capillary pressure effect

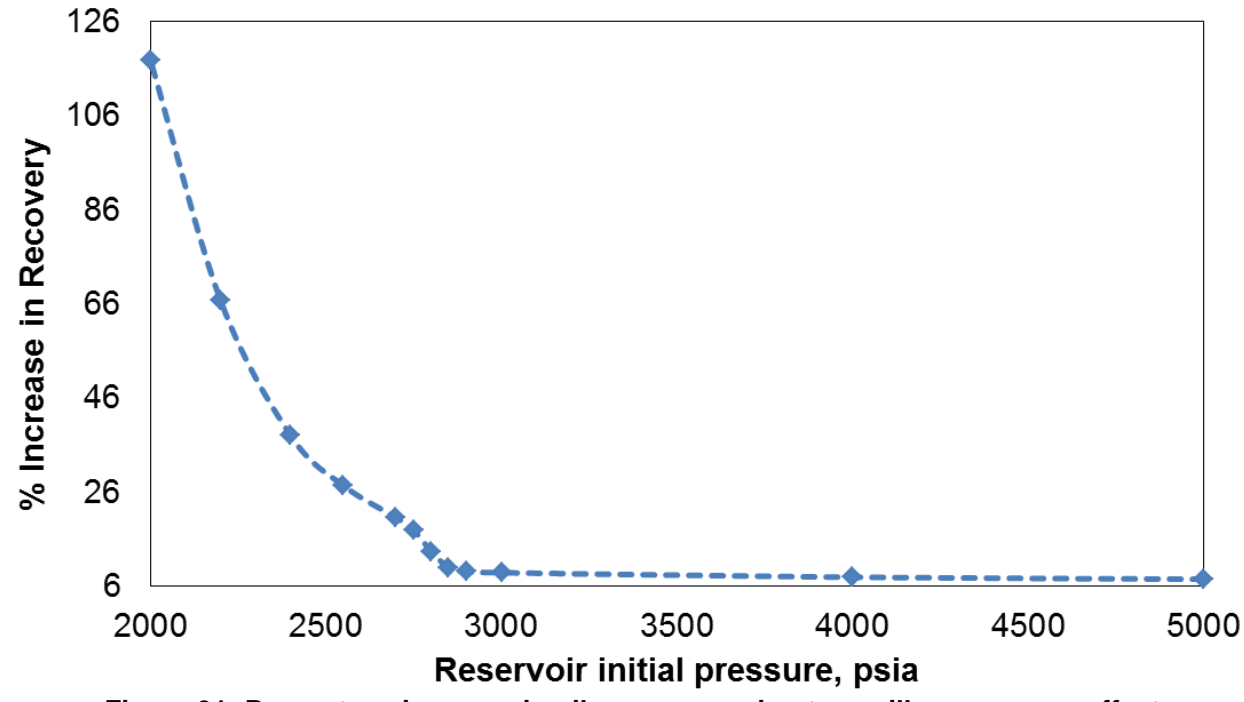

Figure 31- Percentage increase in oil recovery owing to capillary pressure effect

The OOIPs with and without capillary pressure are plotted versus reservoir initial pressure in Figure 29. As shown, when capillary pressure is included in reserve calculations, the estimated OOIP is larger. The percentage increase in OOIP owing to capillary pressure as a function of reservoir initial pressure is shown in Figure $\mathbf{3 0}$ for different reservoir initial pressures. There is no change in OOIP for reservoir initial pressures higher than the bubble-point pressure as there is no gasoil capillary pressure for undersaturated reservoirs. For initial pressures from the original bubble-point pressure to the reduced bubble-point pressure, there is a sudden change in OOIP with and without capillary pressure. The reason for this large contrast is that the reservoir with capillary pressure is undersaturated while the one without capillary pressure is initially saturated at those initial pressures. Thus, the effect of capillary pressure in that pressure range is to convert an initially saturated reservoir to an initially undersaturated one and consequently to increase OOIP owing to a reduced bubble-point pressure. The percentage increase in recoveries after a certain time (here after 300 days) follows the same trend as OOIP (shown in Figure 31). Generally, the increase in production with capillary pressure included in the flash calculations is more pronounced when the reservoir is initially saturated since capillary pressure influences the entire reservoir from the beginning (gas and oil are present for all times). For initially undersaturated reservoirs, there is little effect of capillary pressure far from the production well as the fluids there remain undersaturated for a long period of time. 


\subsection{Case 4: Embedded discrete fracture model and reservoir initial pressure}

In this section, a more realistic description of a shale reservoir is examined by including a transverse fracture in the model. We use the embedded discrete fracture model (EDFM) approach as described by Moinfar et al. (2013). The matrix contains small pores and the effect of high capillary pressure on fluid properties is large, while there is no such effect in the fracture owing to its large effective pore size. Table 4 summarizes the reservoir and fracture properties used. The reservoir temperature is $240^{\circ} \mathrm{F}$ and reservoir fluid is again Bakken oil with a bubble point of 2860 psia (with zero capillary pressure). The initial water saturation in the matrix is 0.25 and it is 0.01 in the fracture. Well pressure is fixed at 500 psia. The relative permeability for the matrix is the same as shown in Figure 20. For the fracture, the relative permeability curves of Figure 20 are modified to have small residual water saturation, critical gas saturation, and residual oil saturation, as shown in Figure 32.

Table 4- Reservoir, fracture and fluid properties for case 4

\begin{tabular}{lc}
\hline Reservoir size, 2D & $750 \mathrm{ft} \times 750 \mathrm{ft}$ \\
\hline Uniform matrix grid block size & $50 \mathrm{ft} \times 50 \mathrm{ft}$ \\
\hline Matrix permeability & $0.02 \mathrm{md}$ \\
\hline Matrix porosity & $6 \%$ \\
\hline Fracture length & $450 \mathrm{ft}$ \\
\hline Fracture width & $0.03 \mathrm{ft}$ \\
\hline Fracture permeability & $1 \mathrm{D}$ \\
\hline Fracture porosity & $50 \%$ \\
\hline Reservoir thickness & $10 \mathrm{ft}$ \\
\hline
\end{tabular}
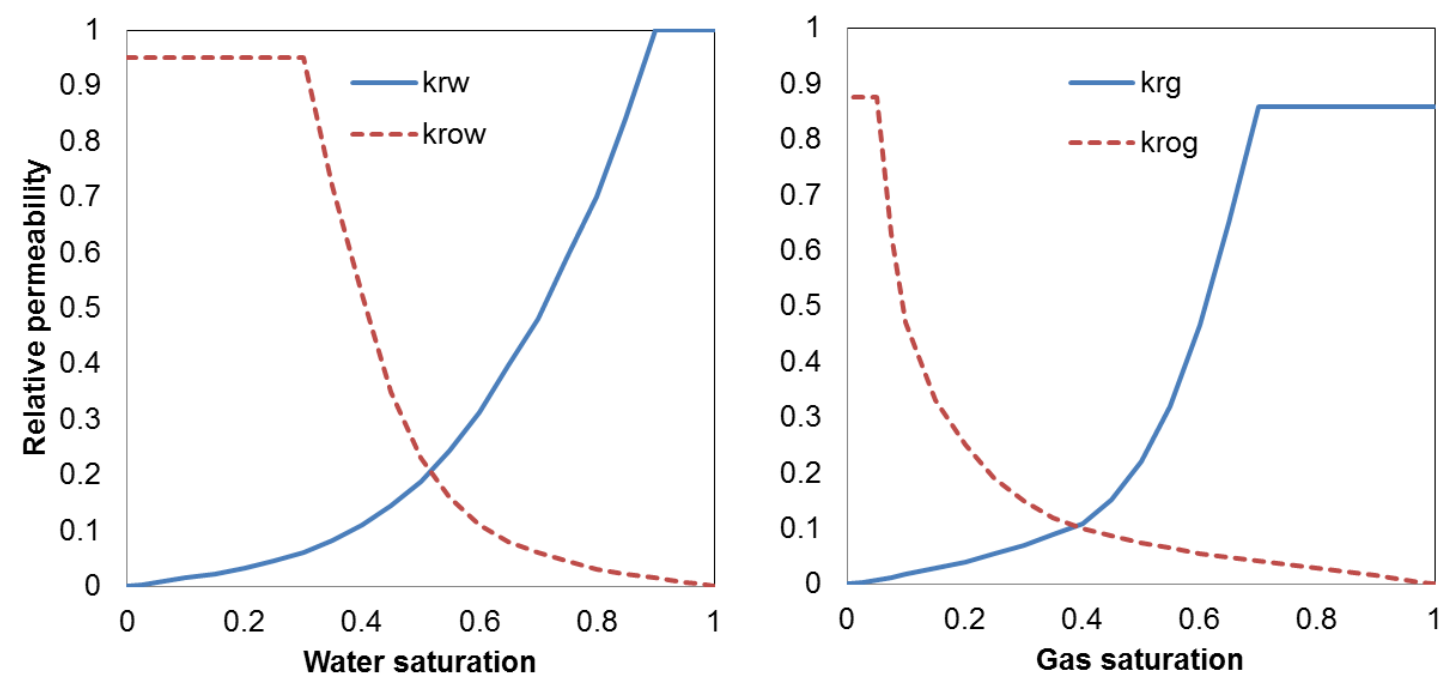

Figure 32- Fracture relative permeability curves for case 4, adopted from Yu et al., 2014

A schematic of the reservoir is shown in Figure 33. Flow is dual-permeability in that flow is allowed from both matrix and fracture grid blocks to the horizontal production well. The effect of capillary pressure on flow is again neglected in the matrix for the same reason noted in Case 3, but gas-oil capillary pressure influences fluid properties in the matrix. 


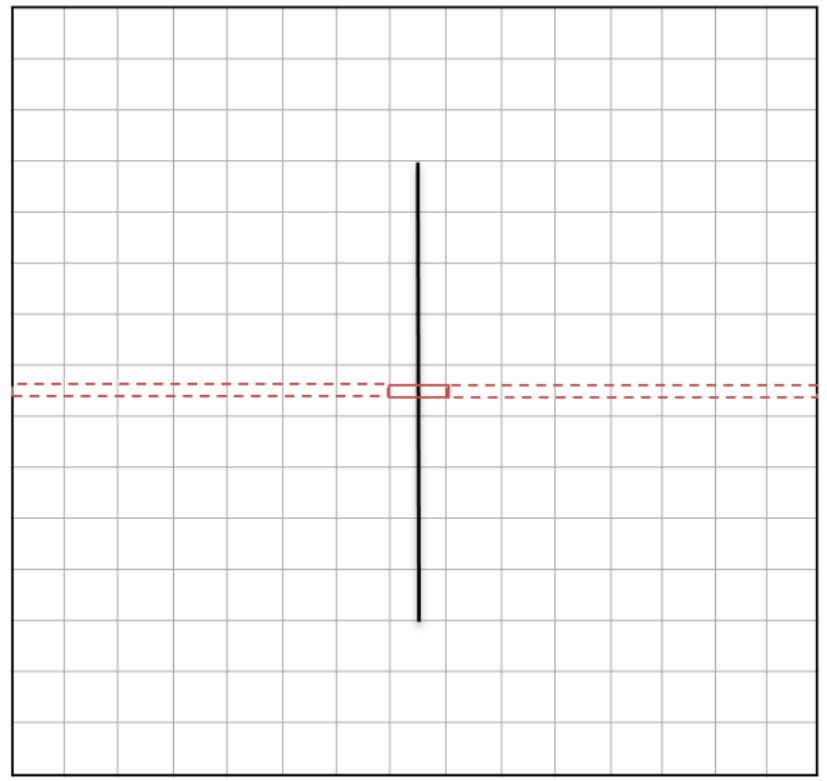

Figure 33- Schematic of the reservoir with a horizontal well and a transverse fracture for case 4

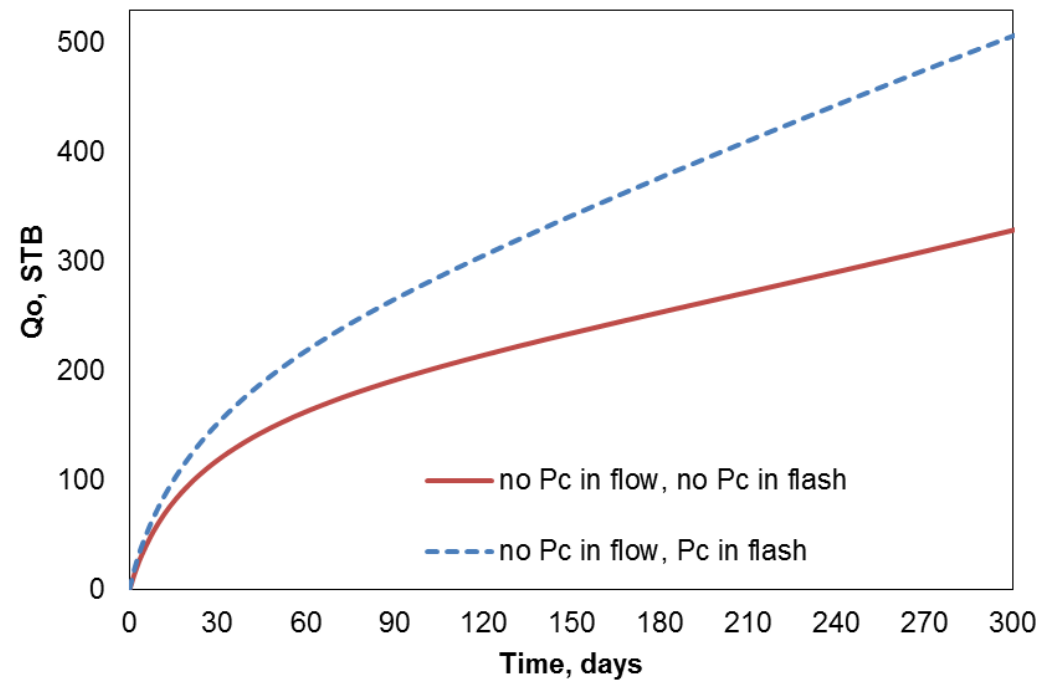

Figure 34- Comparison of cumulative oil production with and without capillary pressure effect on flash with reservoir initial pressure of 2500 psia 


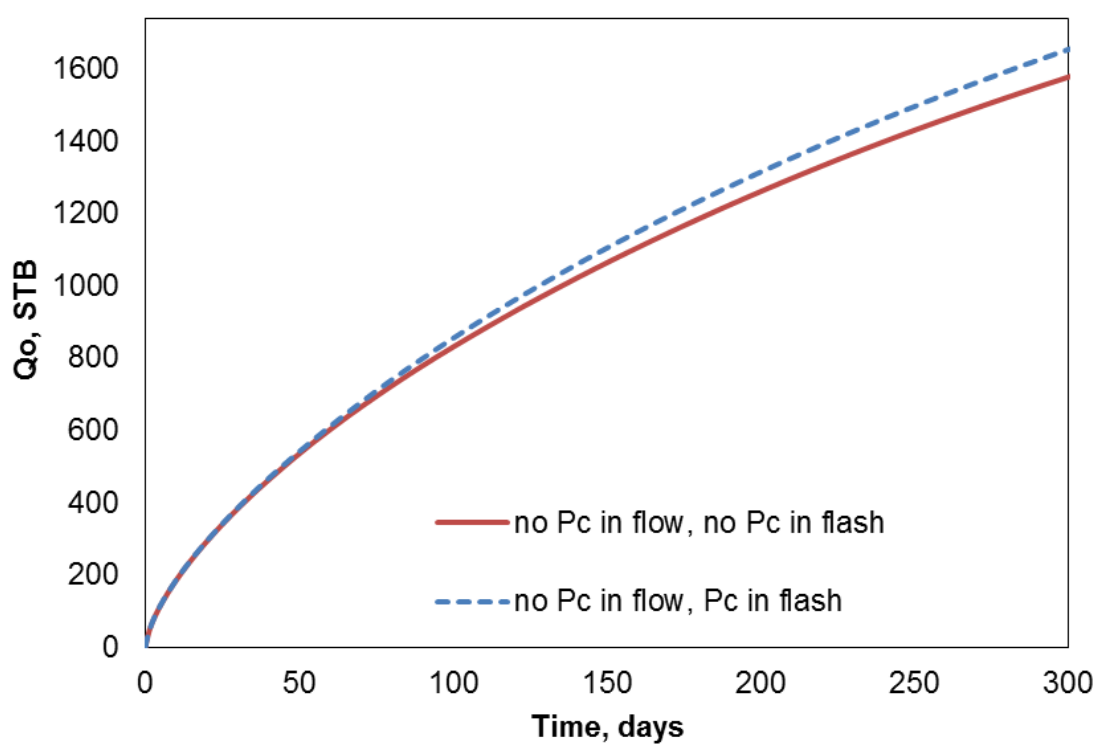

Figure 35- Comparison of cumulative oil production with and without capillary pressure effect on flash with reservoir initial pressure of 5000 psia

Figures 34 and 35 give the cumulative oil production with and without capillary pressure included in the flash calculation for reservoir initial pressures of 5000 psia and 2500 psia (initially undersaturated and saturated respectively). After 300 days, there is a $56 \%$ increase in oil production for 2500 psia, while there is only a $7 \%$ increase in production due to high capillary pressure for 5000 psia. For an initial pressure of 5000 psia, the reservoir is initially undersaturated and after 300 days only a small portion of the reservoir has two phase flow. Thus, the effect of gas-oil capillary pressure on fluid properties is only important in a small region of the reservoir for that example. Further, the impact of capillary pressure on OOIP is zero when the initial pressure is above the bubble-point pressure as it is for 5000 psia. For initial pressure of 2500 psia, however, the reservoir is initially saturated and gas-oil capillary pressure impacts the fluid properties of the entire reservoir immediately, and thus significantly affects production. OOIP is also significantly increased when capillary pressure is included, and subsequently cumulative oil production is more affected. These increases are consistent with the results observed when a stimulated reservoir volume was used in Case 3.

\section{Summary and Conclusions}

We demonstrated how to include the impact of capillary pressure on phase behavior for black-oil simulation models using a compositionally consistent approach. In this novel approach, the bubble-point (or dew-point) becomes a function of both solution gas-oil ratio, and the level of capillary pressure. Further, capillary pressure is a function of pressure-dependent interfacial tension and saturation-dependent pore size distribution (PSD). The method relies on generating pre-tabulated black-oil data using an accurate cubic equation-of-state for several pore sizes. The notion of "effective pore size" is used to interpolate between the pre-tabulated data, where the effective pore size is a function of the gas saturation for a water-wet reservoir. The new compositionally-extended black-oil model is fully-implicit and simulation results are demonstrated for the Bakken oil reservoir. The results from the novel black-oil model were also compared to a fully-implicit compositional simulator also developed to include capillary pressure in the flash calculations. The main conclusions are:

- The new black oil model is robust, and easy to implement using the compositional approach. The model is applicable to any production scenarios and it could also be easily used for volatile-oil or gas condensates as both $R_{\mathrm{s}}$ and $\mathrm{R}_{\mathrm{v}}$ are included in the calculations. In this paper, we focused solely on the black oil of the Bakken.

- Primary recoveries increase when the effect of capillary pressure on phase behavior is included. The increase is in the range of $5-10 \%$ OOIP for the cases considered where the initial reservoir pressure is above the bubble-point pressure. Similar recovery increases occur when the reservoir contains a stimulated reservoir volume or discrete fracture.

- Primary recoveries increase substantially (by over $100 \%$ for some cases) when the initial reservoir pressure is below the bubble-point pressure and capillary pressure effects on flash calculations are included. The large increase is the result of fluid property changes and a small, but significant increase in the OOIP when capillary pressure is included.

- When capillary pressure is included OOIP is increased by up to $6 \%$ for the initially undersaturated reservoirs considered. This is because capillary pressure decreases the gas saturation for black oil reservoirs. 
- The change in black-oil properties (densities, viscosities, solution gas-oil ratio, volatile oil-gas ratio) is nearly linear with pore curvature thus, linear interpolation is reasonably accurate.

- The recoveries and pressures agree well to those of detailed fully-compositional simulations with and without the effect of capillary pressure on phase behavior

- Using the pore-size distribution (PSD) is more accurate than applying a fixed-pore size approach as is current practice. The increase in recoveries with capillary pressure included in flash calculations decreases somewhat using PSD.

\section{Acknowledgements}

This research was partly sponsored by the Unconventional Natural Resources Consortium (UNRC) and the Enhanced Oil Recovery Consortium (EORC) at the EMS Energy Institute at the Pennsylvania State University. We also thank the Hess Corporation for the mercury injection data for the Bakken core samples. Dr. Russell T. Johns is the Chair and Beghini Professor of Petroleum and Natural Gas Engineering in the John and Willie Leone Family Department of Energy and Mineral Engineering at Penn State.

\section{Nomenclature}

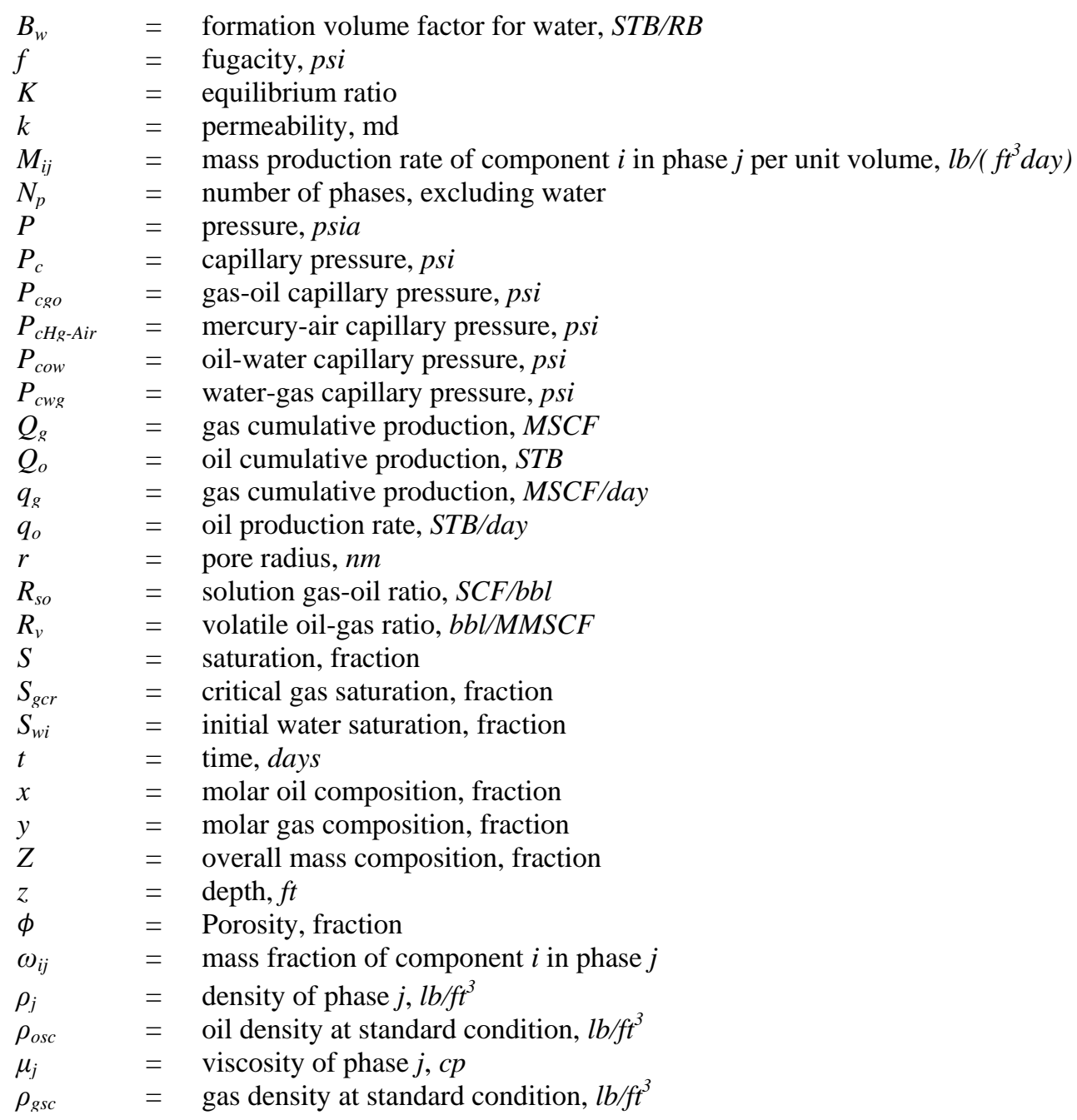

\section{Acronyms}

IFT $=$ Interfacial tension, dyne/cm 
$\begin{array}{ll}\text { PSD } & =\text { Pore-size distribution } \\ \text { PTR } & =\quad \text { Pore throat radius, } \mu m\end{array}$

\section{Subscripts and Superscripts}

$i=$ component $i$

$j \quad=\quad \operatorname{phase} j$

$g \quad=\quad$ gas (vapor) phase

$o=$ oil (oleic) phase

$w \quad=\quad$ water(aqueous) phase

\section{Unit conversion}

Density

Gas production

Interfacial tension

Length

Oil production

Permeability

Pressure

Solution gas-oil ratio

Viscosity

Volatile oil ratio

\section{Field Units}

$l b / f t^{3}$

$S C F$

dyne/cm

$f t$

$S T B$

md

Psia

SCF/bbl

cp

bbl/MMSCF
SI Units

$\begin{array}{ll}= & 16.018 \mathrm{~kg} / \mathrm{m}^{3} \\ = & 0.028 \mathrm{~m}^{3} \\ = & 0.001 \mathrm{~N} / \mathrm{m} \\ = & 0.305 \mathrm{~m} \\ = & 0.159 \mathrm{~m}^{3} \\ = & 9.869 \mathrm{e}-16 \mathrm{~m}^{2} \\ = & 6894.757 \text { Pascal } \\ = & 0.028 / 0.159 \mathrm{~m}^{3} / \mathrm{m}^{3} \\ = & 0.001 \text { Pascal.sec } \\ = & 0.159 /(0.028 \mathrm{e} 6) \mathrm{m}^{3} / \mathrm{m}^{3}\end{array}$

\section{References}

Ayirala S.C., Rao D.N., A new Parachor model to predict dynamic interfacial tension and miscibility in multicomponent hydrocarbon systems, Colloid and Interface Science, 299, 321-331, 2006.

Brusllovsky A.L., Mathematical simulation of phase behavior of natural multicomponent systems at high pressure with an equation of state, SPE reservoir engineering, 1992.

Coats K. H., An equation of state compositional model, SPE Journal, Vol 20, issue 05, 1980.

Comisky J. T., Newsham K., Rushing J. A., Blasingame, T. A., A comparative study of capillary-pressure-based empirical models for estimating absolute permeability in tight gas sands, presented at SPE Annual Technical Conference and Exhibition, Anaheim, California, 2007.

Du L., Chu L., Understanding anomalous phase behavior in unconventional oil reservoirs, presented at SPE Canadian Unconventional Resources Conference, Calgary, Alberta, Canada, 2012.

Firincioglu T., Ozkan E., Ozgen C., Thermodynamics of multiphase flow in unconventional liquids-rich reservoirs, presented at the SPE ATCE, San Antonio, Texas, 2012.

Huan G.R., A flash black oil model, presented at the SPE Middle East Oil Technical Conference and Exhibition, Bahrain, 1985.

Jin L., Ma Y., Jamili A., Investigating the effect of pore proximity on phase behavior and fluid properties in shale formations, presented at the SPE Annual Technical Conference and Exhibition, New Orleans, Louisiana, 2013.

Jin Z., Firoozabadi A., Thermodynamic modeling of phase behavior in shale media, SPE Journal, Vol 21, Issue 01, 190-207, 2016.

Kuila U., Prasad M., Surface area and pore-size distribution in clays and shales, presented at the SPE Annual Technical Conference and Exhibition, Denver, Colorado, 2011.

Leverett M.C., Capillary behavior in porous solids, Transactions of the AIME, Vol. 142, Issue01,152-169,1941. 
Ma Y., Jamili A., Modeling the effects of porous media in dry gas and liquid rich shale on phase behavior, presented at the SPE Improved Oil Recovery Symposium, Tulsa, Oklahoma, USA, 2014.

Macleod, D.B., On a relation between surface tension and density, Trans., Faraday Soc., J. Chem. Soc., Vol. 125, 38-42, 1923.

Moinfar A., Varavei A., Sepehrnoori K., Johns R., Development of an efficient embedded discrete fracture model for 3D compositional reservoirs simulation in fractures reservoirs, SPE Journal, Vol 19, issue 02, 2014.

Nojabaei B., Johns R.T., Chu L., Effect of capillary pressure on phase behavior in tight rocks and shales, SPEREE, Vol.16, 281-289, 2013.

Peaceman, D.W., Interpretation of well-block pressures in numerical reservoir simulation, Trans. AIME, Vol.253, 183-94, 1978.

Pedersen K.S., Christensen P.L., Phase behavior of petroleum reservoir fluid, CRC Press, Taylor \& Francis Group, 2007.

Peng, D. Y., and Robinson, D. B., A new two-constant equation of state, industrial and engineering chemistry: fundamentals, Vol.15, 5964, 1976.

Ping G., Liangtian S., Li S, Lei S., A theoretical study of the effect of porous media on the dew point pressure of a gas condensate, presented at SPE Gas Technology Symposium and Exhibition, Calgary, Alberta, 1996.

Rezaveisi M., Sepehrnoori K., Pope G.A., Johns R. T., Compositional simulation including effect of capillary pressure on phase behavior, presented at the SPE Annual Technical Conference and Exhibition, Houston, Texas, 2015.

Shoaib, S., Hoffman B. T., CO2 Flooding the Elm Coulee Field, presented at SPE Rocky Mountain Technology Conference, Denver, Colorado, 2009.

Singh S.K., Sinha A., Deo G., Singh J.K., Vapor-liquid coexistance, critical properties, and surface tension of confined alkanes, The Journal of Physical Chemistry, Vol. 113,7170-7180, 2009.

Sugden S., The variation of surface tension with temperature and some related function, J. Chem. Soc, Vol. 125, 32-41, 1924.

Wang L., Parsa E., Gao Y., Ok J. T., Neeves K., Yin X., Ozkan, E., Experimental study and modeling of the effect of nanoconfinement on hydrocarbon phase behavior in unconventional reservoirs, presented at the Western Northern American and Rocky Mountain Joint Regional Meeting, Denver, Colorado, 2014.

Wang Y., Yan B., Killough J., Compositional modeling of tight oil using dynamic nanopore properties, presented at the SPE Annual Technical Conference and Exhibition, New Orleans, Louisiana, 2013.

Wong T.W., Firoozabadi A., Nutakki R., Aziz K., A comparison of two approaches to compositional and black oil simulation, presented at the $9^{\text {th }}$ SPE Symposium on Reservoir Simulation, San Antonio, Texas, 1987.

Zhou D., Blunt M., Wettability effects in three-phase gravity drainage, Journal of Petroleum Science and Engineering 20, $203-211,1998$. 